\title{
Investigation and Control of VIVs with Multi-Lock-in Regions on Wide Flat Box Girders
}

\author{
Bo Wu, ${ }^{1,2}$ Liangliang Zhang, ${ }^{1,2}$ Yang Yang, ${ }^{1,2}$ Lianjie Liu, ${ }^{1,2,3}$ and Haohong $\mathrm{Li}^{1}$ \\ ${ }^{1}$ Key Laboratory of New Technology for Construction of Cities in Mountain Area, Chongqing 400045, China \\ ${ }^{2}$ School of Civil Engineering, Chongqing University, Chongqing 400045, China \\ ${ }^{3}$ Department of Highway Engineering, Chongqing Construction Science Research Institute, Chongqing 400017, China \\ Correspondence should be addressed to Liangliang Zhang; zll200510@126.com and Yang Yang; yy20052710@163.com
}

Received 19 December 2016; Revised 10 February 2017; Accepted 20 February 2017; Published 14 March 2017

Academic Editor: Seiichiro Katsura

Copyright (c) 2017 Bo Wu et al. This is an open access article distributed under the Creative Commons Attribution License, which permits unrestricted use, distribution, and reproduction in any medium, provided the original work is properly cited.

On the preliminary designing of a wide flat box girder with the slenderness ratio 12, vertical and torsional vortex-induced vibrations (VIV) are observed in wind tunnel tests. More than one lock-in region, which are defined as "multi-lock-in regions," are recorded. Therefore, suspicions should be aroused regarding the viewpoint that wide box girders are aerodynamic friendly. As the three nascent vortexes originating at the pedestrian guardrails and inspection rails shed to near-wake through different pathways with different frequencies, the mechanisms of VIVs and multi-lock-in regions are analyzed to be determined by the inappropriate subsidiary structures. A hybrid method combining Large Eddy Simulation (LES) with experimental results is introduced to study the flow-structure interactions (FSI) when undergoing VIVs; the vortex mode of torsional VIV on wide flat box girders is defined as "4/2S," which is different from any other known ones. Based on the mechanism of VIV, a new approach by increasing ventilation rate of the pedestrian guardrails is proved to be effective in suppressing vertical and torsional VIVs, and it is more feasible than other control schemes. Then, the control mechanisms are deeper investigated by analyzing the evolution of vortex mode and FSI using Hybrid-LES method.

\section{Introduction}

Three Gorges Area has been playing decisive roles in southwest China and witnessing rapid developments in bridge constructions. Suspension bridges with flat box girders are widely used in long-span bridge constructions due to their high traffic volume. With the spans and widths increasing, those newly built bridges become more and more flexible with little damping capacity and hence more sensitive to wind loads, which always give rise to more frequently observed high-level wind-induced responses [1].

Vortex-induced vibration (VIV) is a resonant phenomenon caused by periodic airflow vortex shedding whose frequencies are close to the natural frequency of the structures [1]. On the VIV of blunt bodies like circular cylinders, comprehensive studies have been performed to investigate the oscillation amplitude, vortex shedding mode, Reynolds numbers effect, and so forth [2-5]. Concerning VIV responses in bridge engineering, although the limited oscillations do not directly destroy a bridge, they cause large displacements and discomfort to the drivers crossing the bridge, conveying a public sense of the bridge not being safe. Besides, VIV s commonly occur with high probability, resulting in long-term fatigue damage. Therefore, investigations on VIV of long-span bridges should be conducted.

There are significant differences between the VIVs of bridge girders and circular cylinders, attributing to different aerodynamic configurations and flow-structure interactions (FSI). Actually, differences also exist between different bridge girders, like " $\pi$ " shape girder, truss girder, single-box girder, twin-box girder, and so forth [6-8]. As for a single-box girder, even the changes in apex of the noses can cause significant differences to the VIV responses, and a bottom plate/side panel angle of $15^{\circ}$ can be designed to eliminate VIV [9]. Wide flat box girder configuration, that is, the width is much larger than the height and hence with large slenderness ratio, is considered to be streamlined-like and aerodynamic friendly. The height is so small compared with the span and width 

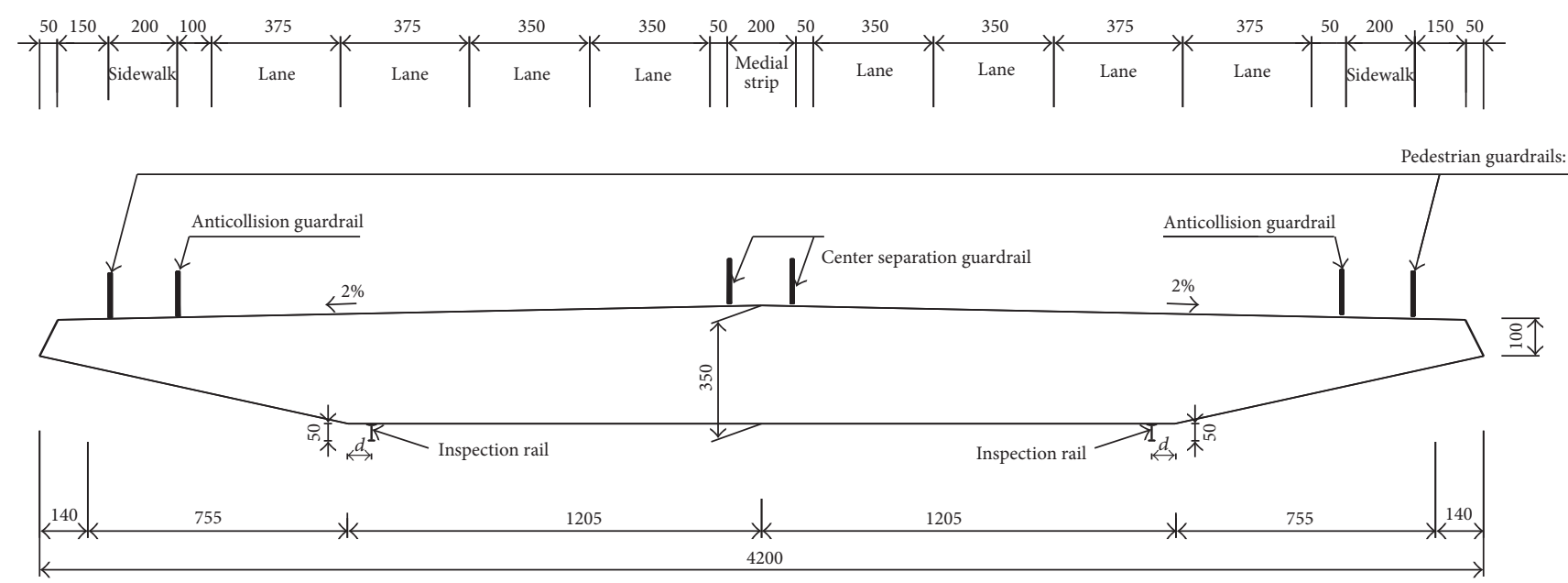

Figure 1: Geometry and dimensions of the bridge decks (unit: $\mathrm{cm}$ ).

that tiny modifications to the transverse details, such as guardrails and inspection rails, can significantly change the aerodynamic characteristics and hence result in volumetric or even qualitative changes to the VIV responses and FSI feedbacks [1]. Several researches mentioned the effects of deck details on aerodynamic performance of bridges $[10,11]$, but they did not focus on wide flat box girders and provide little knowledge about the influence mechanisms.

Wind tunnel tests are aimed to predict the lock-in regions and amplitudes of VIV and to carry out specific optimizations or control measures to the preliminary designed configurations. Computational fluid dynamics (CFD) is another applicable method to obtain aerodynamic characteristics of bridge decks. One of its advantages is the capacity in providing the details of fluid field, which allows a deeper analysis of the FSI mechanism. In previous studies, numerical simulations of VIV were studied using 3D Large Eddy Simulation (LES) $[12,13]$, but they did not deal with the flow evolutions and the bridge deck was simplified neglecting all the section details. Consequently, the flow fields they presented were different form actual ones.

In the case that the maximum VIV amplitude of the designed bridge deck exceeds the allowable value, additional appendages, such as deflectors, suppression boards, and external dampers, are attached to the basic deck to change the flow field so as to avoid or suppress VIV $[1,5]$. However, all of these measures have a penalty of adding substantial mass to the bridge and dissatisfied impressions to the original designing works.

The main objective of this paper is to introduce a more economical and convenient approach in controlling VIVs and to gain a deeper understanding of the mechanisms of VIVs on wide flat box girders. The organization is as follows: in Section 2, the backgrounds of a wide flat box girder are described and wind tunnel tests are carried out to determine whether the preliminary designed bridge deck undergoes VIV or not. In Section 3, a hybrid method combining numerical simulations with experimental results is introduced to study the FSI processes when the bridge deck is undergoing VIV, especially that the numerical model is simulated taking all the subsidiary members into consideration, which is an improvement to the previous studies mentioned above. Then the numerical method is validated to determine its accuracy. In Section 4, the occurrence mechanism and flow evolutions of VIV on wide flat girders are discussed. The cause of multilock-in regions is analyzed. In Section 5, a new approach based on the occurrence mechanism is introduced to control VIVs; its efficiencies are deeper investigated by analyzing the evolution of vortex patterns and FSI.

\section{VIV Responses of Wide Flat Box Girders}

2.1. Backgrounds. CUN-TAN Yangtze Bridge, consisting of a main bridge $(880 \mathrm{~m})$ and two approach bridges $(250 \mathrm{~m})$, is one of the key parts of Chongqing Airport Expressway. A suspension structure with the rise-span ratio of $1 / 8.8$ is designed for the main bridge. A box girder with the width $42 \mathrm{~m}$ and the height $3.5 \mathrm{~m}$, namely, a slenderness ratio 12 , is applied for the bridge deck. A bidirectional 2\% slope is designed for weathering considerations. The geometry and main dimensions are shown in Figure 1.

2.2. Wind Tunnel Test Setups. Both stationary and dynamic wind tunnel tests are conducted in the Industrial Wind Tunnel of Southwest Jiaotong University (XNJD-1), Chengdu, China. The dimension of the test section is $2.4 \mathrm{~m} \times 2.0 \mathrm{~m} \times 16.0 \mathrm{~m}$ (width $\times$ height $\times$ length), with the incoming wind speed $U$ adjustable from $1.0 \mathrm{~m} / \mathrm{s}$ to $45.0 \mathrm{~m} / \mathrm{s}$ (turbulent intensity < $0.5 \%)$. The section model of the girder with the scaling ratio of 1:60 is manufactured using high-quality light wood and plastic, with the length $(L) 2.095 \mathrm{~m}$, the width $(B) 0.700 \mathrm{~m}$, and the height $(H) 0.058 \mathrm{~m}$. It is supported by 8 springs which are attached symmetrically on the scaffolds to yield vertical and torsional degrees of freedom at the natural frequencies. To avoid their interference on the flow filed, the springs and scaffolds are mounted outside the test section. Two laser displacement sensors are placed symmetrically to the longitudinal axis of the model with a lateral spacing $40.0 \mathrm{~cm}$ to measure the oscillation information. The sampling frequency is set at $256 \mathrm{~Hz}$. 
TABLE 1: Design parameters of wind tunnel tests.

\begin{tabular}{lcccc}
\hline Parameters & Symbol & Actual values & Required values & Testing values \\
\hline Height $(\mathrm{m})$ & $D$ & 3.5 & 0.0583 & 0.058 \\
Width $(\mathrm{m})$ & $B$ & 42.0 & 0.7 & 0.700 \\
Length $(\mathrm{m})$ & $L$ & 880 & 7.667 & 7.095 \\
Mass/unit length $\left(\mathrm{kg} \cdot \mathrm{m}^{-1}\right)$ & $m$ & 27600 & 0.3987 & 0.399 \\
Mass moment of inertia/unit length $\left(\mathrm{kg} \cdot \mathrm{m}^{2}\right) \cdot \mathrm{m}^{-1}$ & $I$ & 5137700 & 0.218 & 2.274 \\
First vertical natural frequency $(\mathrm{Hz})$ & $f_{v}$ & 0.1745 & 0.389 & 0.442 \\
Vertical damping ratio (\%) & $C$ & 0.5 & 5.417 & 5.404 \\
First torsional natural frequency $(\mathrm{Hz})$ & $f_{t}$ & 0.3973 & 0.439 & 0.422 \\
Torsional damping ratio (\%) & $C_{\theta}$ & 0.5 & & $<0.5 \%$ \\
Turbulent intensity (\%) & & & & \\
\hline
\end{tabular}

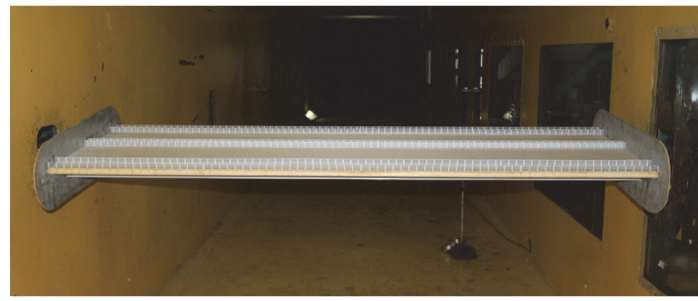

FIGURE 2: Dynamic testing setups.

In the dynamic tests, the incoming wind speeds $(U)$ are increased stepwise with the increment of approximately $0.02 \mathrm{~m} / \mathrm{s} \sim 0.1 \mathrm{~m} / \mathrm{s}$ (smaller in lock-in regions) in the range of $1.0 \sim 15.0 \mathrm{~m} / \mathrm{s}$, with an experimental/actual ratio of 4.72 , and the corresponding Reynolds numbers $(\mathrm{Re})$ are in the range of $4.7 \times 10^{4} \sim 7.0 \times 10^{5}$.

All the testing parameters are listed in Table 1 . The natural frequencies of vertical and torsional degrees of freedom are both based on the first-order vibration mode, and the corresponding allowable oscillation amplitudes of vertical and torsional VIV are $229.2 \mathrm{~mm}$ and $0.2733 \mathrm{rad}\left(15.67^{\circ}\right)$, respectively, specified by Chinese Wind-Resistant Design Specification for Highway Bridges [14].

The tests are conducted at attack angles $0^{\circ}, \pm 3^{\circ}$, and $\pm 5^{\circ}$; Figure 2 is a demonstration of the testing setups.

2.3. Experimental Results. According to the testing results, no VIV is observed in case of the bare deck, no matter the attack angle is $0^{\circ}, \pm 3^{\circ}$, or $\pm 5^{\circ}$.

Concerning the preliminary designed completed deck (call it Case \#0), there are no VIVs occurring at attack angles $0^{\circ},-3^{\circ}$, and $-5^{\circ}$. However, both vertical and torsional VIVs are recorded at attack angles $+5^{\circ}$ and $+3^{\circ}$ and hence they are what the following discussions mainly focused on.

For convenience, the reduced wind speed $\left(U_{r}\right)$ adopted in this paper is based on the width $(B=0.7 \mathrm{~m})$ and the vertical natural frequency $\left(f_{v}=2.274 \mathrm{~Hz}\right)$ and is calculated as

$$
U_{r}=\frac{U}{\left(f_{v} B\right)} .
$$

The relationship between RMS displacement of VIV and $U_{r}$ is shown in Figures 3 and 4.
At attack angle $+5^{\circ}$, the lock-in region of vertical VIV is $U_{r}=1.068 \sim 2.249$, and the maximum RMS of nondimensional amplitude $(y / D)$ is $0.122(425.036 \mathrm{~mm}$ in actual size) at $U_{r}=2.092$, which is $85.6 \%$ greater than the allowable value $(229.2 \mathrm{~mm})$. The lock-in region of torsional VIV is $U_{r}=$ 2.199 2.959, and the maximum RMS amplitude is $1.197^{\circ}$ at $U_{r}=2.532$, which is lower than the allowable value $\left(15.67^{\circ}\right)$.

At attack angle $+3^{\circ}$, the lock-in region of vertical VIV is $U_{r}=1.746 \sim 2.155$. Apart from this, vertical VIV responses occur at $U_{r}=0.898$ and 1.269 . The maximum RMS $y / D$ is $0.065(227.710 \mathrm{~mm}$ in actual size $)$ at $U_{r}=2.048$, which is lower than the allowable value. It is interesting to record two lock-in regions of torsional VIV during $U_{r}=1.445 \sim 1.696$ and $U_{r}=2.199 \sim 2.984$; call them the subregion and the main region, respectively. The maximum RMS amplitude is $0.337^{\circ}$ at $U_{r}=2.564$, which is lower than the allowable value.

\section{Numerical Simulations}

To obtain deeper knowledge of the FSI processes when the bridge deck is undergoing VIV, and hence the occurrence mechanisms of the poor aerodynamic performances of the preliminary designed deck Case \#0, Computational Fluid Dynamics (CFD) is applied for fluid filed.

Vortex-induced vibrations of bridges are processes of FSI whose numerical model consists of the fluid dynamics and the motion dynamics. In the lock-in region of VIV, the fluid dynamics are controlled by the motion of the bridge deck and in turn influence the motion simultaneously [15].

As the motion of the bridge deck has been already known through experimental results, once it is inputted into the numerical model as the motion function, the numerical simulation can be solved only by solving the fluid dynamics problem with moving boundaries [16]. Detailedly, the motion of the bridge deck is simplified to be a mass-spring-damper system with vertical and torsional degrees of freedom, as the oscillation is mainly controlled by the first-order signals in a weak nonlinear resonance system, and the higherorder components are negligible $[5,17]$. Consequently, the measured time-history oscillation amplitudes are band-pass filtered to obtain the first-order components. Then, the firstorder oscillation amplitudes are inputted into CFD using a 


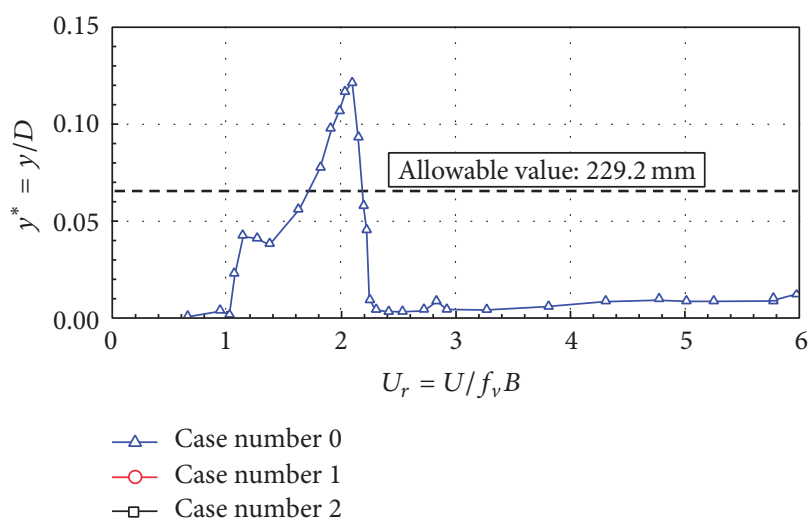

(a) $\alpha=+5^{\circ}$

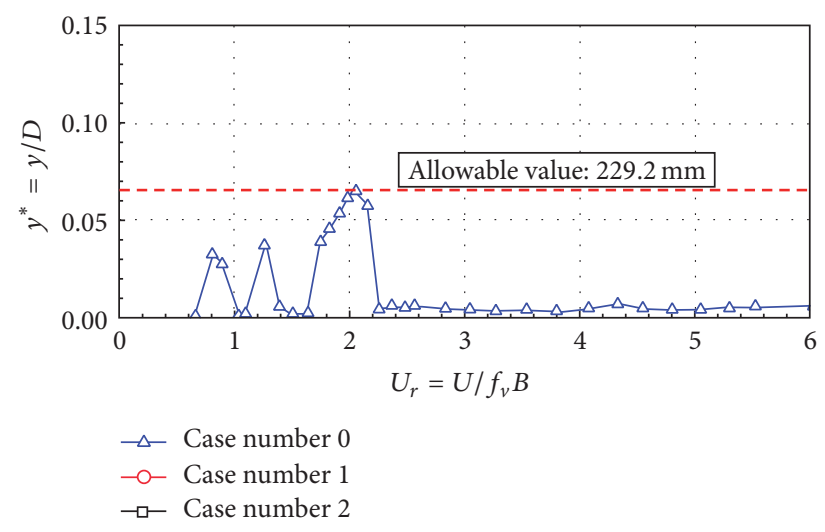

(b) $\alpha=+3^{\circ}$

Figure 3: RMS of vertical displacement of Case \#0.

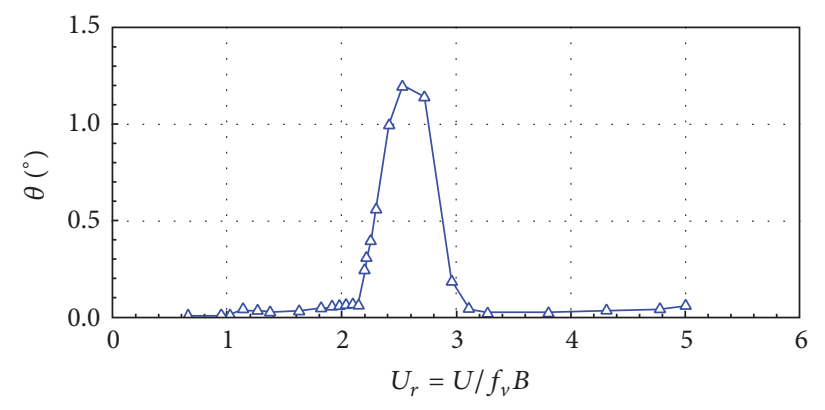

$\neg$ Case number 0

- - Case number 1

$\rightarrow-$ Case number 2

(a) $\alpha=+5^{\circ}$

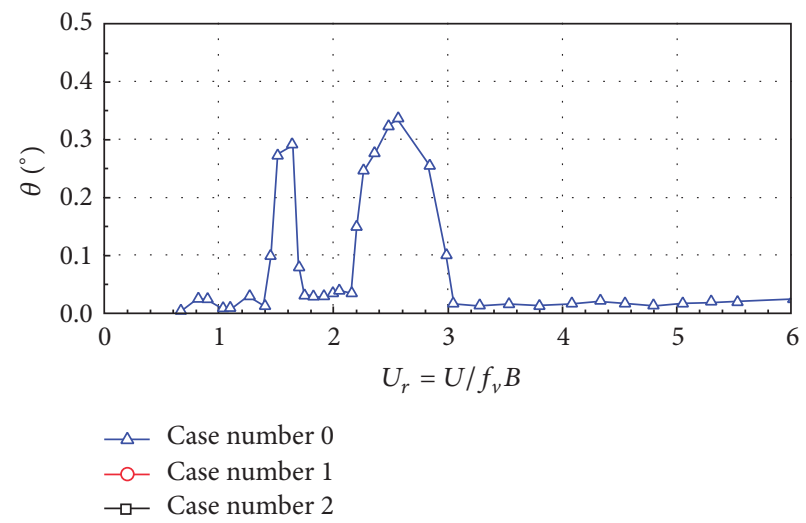

(b) $\alpha=+3^{\circ}$

FIgURE 4: RMS of torsional displacement of Case \#0.

User Defined Function (UDF) to serve as the motion function of the bridge deck and the moving boundary.

As the motion dynamic of the numerical model is exactly the same as testing results, which give rise to an elimination to the coupling errors, this hybrid-CFD method is more accurate than traditional CFD simulations $[16,18]$ and hence is of essential importance in revealing the mechanisms of VIV which have been recorded.

3.1. Settings. The CFD calculations are carried out using ANSYS Fluent 15.0 code. The turbulent simulations are based on Large Eddy Simulation (LES), in which the vortexes of turbulent flow are classified as larger and smaller ones. The larger ones are anisotropic and solved by numerical solutions of differential equations. While the smaller ones are considered isotropous and simulated by an implicit modeling of the Sub-Grid Scale (SGS) [19]. Smagorinsky-Lilly SGS model is adopted for its best capability in reproducing pressure distributions and flow separation compared to other turbulence models. The pressure-velocity decoupling is achieved by the SIMPLE algorithm. Bounded Central Difference scheme for convective terms and the Second-Order Implicit scheme for unsteady terms are used.
Time step $\Delta t=0.005 \mathrm{~s}$ is proved to be time-independent by several tentative calculations [20]. The convergence criteria is that if the normalized residual is less than $10^{-5}$, the iteration process stops.

In a whole process of Hybrid-LES, the numerical model is fully computed under stationary conditions at first, and then the UDF is activated to carry out a dynamic calculation using dynamic meshing technology.

3.2. Fluid Domain and Boundaries. The computational domain reproduces the geometry of the bridge deck in scaling ration of $1: 60$. The length of the model is $1 / 8$ the width of testing room $(0.2625 \mathrm{~m})$, mainly concerning computational efficiency. All the subsidiary members are taken into consideration: the pedestrian guardrails, the center separation guardrails, and the inspection rails. Other sectional details are consistent with those in the wind tunnel tests, which are shown in Figure 5.

The computational domain is formed in the preprocessing code GAMBIT and has considered 24 deck chords $(B)$ before, 44 deck chords after, and 18 deck chords up/down the bridge deck model to ensure domain-independence. Furthermore, in order to avoid distortions when the grids 


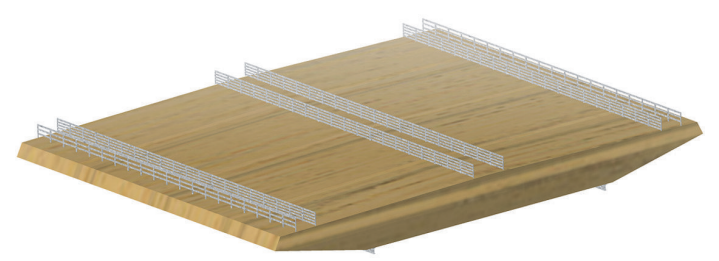

FIgURE 5: Details of computational model in CFD simulations.

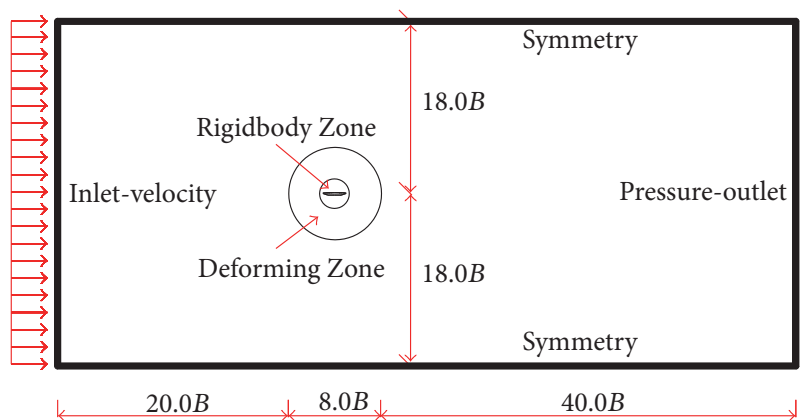

FIGURE 6: Geometry and boundary conditions of VIV simulation in CFD.

are in motion, the computational domain is discretized into 4 parts from inside to outside similar to the approach proposed by Fransos and Bruno [21]: the outer walls of the bridge model, the Rigidbody Zone, the Deforming Zone, and the External Stationary Zone [12]. By passing the prescribed motion of the model to the girds of the Rigidbody Zone using DEFINE_CG_MOTION macro in the UDF, the Rigidbody Zone oscillates together with the model allowed by a dynamic meshing method used in the Deforming Zone. To mitigate its impact on the Deforming Zone and manage varying attack angles without modifying the refined mesh, the Rigidbody Zone is set to be a circle with the diameter of $1.2 B$. As for the External Stationary Zone, it remains stationary when the grids of the Deforming Zone are in motion. The dimensions are shown in Figure 6.

Boundary conditions are set to reproduce the wind tunnel test setup and also shown in Figure 6, which are surrounded by $\Gamma^{\text {model }}, \Gamma^{\text {up }}, \Gamma^{\text {down }}, \Gamma^{\text {in }}$, and $\Gamma^{\text {out }}$ and specified as follows:

$\Gamma^{\text {model }}$ : no-slip wall conditions, the outer edges of the bridge and its subsidiary members; thus the speed of the fluid and the bridge are identical at the interface.

$\Gamma^{\text {up }}$ and $\Gamma^{\text {down }}:$ the symmetry conditions.

$\Gamma^{\text {in }}$ : the velocity-inlet conditions, wind flows normal to the boundary, and the incoming wind speed, turbulent intensity, and viscosity are consistent with those in the wind tunnel tests.

$\Gamma^{\text {out }}$ : the pressure-outlet conditions, allowing for a full development of the turbulence wake.

3.3. Meshing. The mesh distributions of the computational domain are defined through refining tests to ensure meshindependent solutions.

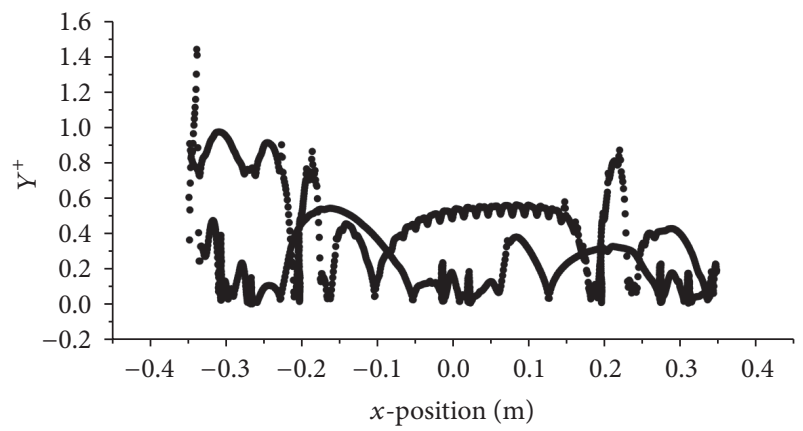

Figure 7: Wall $Y^{+}$value of Case $\# 0\left(U_{r}=2.092\right)$.

The mesh quality of the boundary layer fitted the bridge deck is of vital importance to the precise solution of turbulence model, and the height of the first layer $\left(y_{w}\right)$ should be determined considering wall $\mathrm{Y}^{+}$value, which is a nondimensional parameter corresponding to $y_{w}$. After several testing calculations, $y_{w}$ is set to be $1.4 \times 10^{-4} B$ and therefore the majority of $Y^{+}$values are limited to less than 1 , as shown in Figure 7 . The fitted boundary mesh consists of 20 layers of structural grids whose spacing grows in the outline direction of the model, from $y_{w}$ to $6.6 \times 10^{-3} \mathrm{~B}$ at the ratio 1.2. The transverse edges of the model are divided by 101 grid points, and the radial by 21 grid points. The remaining parts of the Rigidbody Zone are meshed by body-fitted paved quadrangular grids, with finer grids used near the subsidiary members.

The Deforming Zone and External Stationary Zone are filled with structural grids with the minimum spacing $1.1 \times$ $10^{-2} \mathrm{~B}$. In order to better capture the flow field characteristics, finer meshes are applied where the flow changes violently.

Furthermore, the grids in the Deforming Zone will be deformed at each iteration time step. The spring-based smoothing method together with dynamic meshing and UDF are applied to adjust the size and shape of the quadrangular grids. In this method, the edges between two grid nodes are idealized as a network of interconnected springs [12].

If the displacement of bridge deck is too large compared with the size of the girds around it, negative mesh volumes are generated due to the deteriorating mesh quality; then the solution will be interrupted by convergence problems. To solve this problem, the Rigidbody Zone and Deforming Zone are therefore set to be concentric circles, which have been mentioned above, to pass the displacement of the bridge deck to those larger grids in the Deforming Zone.

A sketch of the mesh distributions of Case \#0 at attack angle $+5^{\circ}$ is shown in Figure 8; the computational domain is constructed with a total of 2,942,000 elements.

3.4. Validations. In a mass-spring-damper system with a vertical freedom, the motion function can be written as

$$
m \ddot{y}+C \dot{y}+k_{y} y=\frac{1}{2} \rho U^{2} B L \cdot C_{L}(t),
$$

where $B$ and $L$ are the width and length of the section model; $C_{L}(t)$ is the coefficient of lift force; $m, C, k_{y}$ are the mass, 


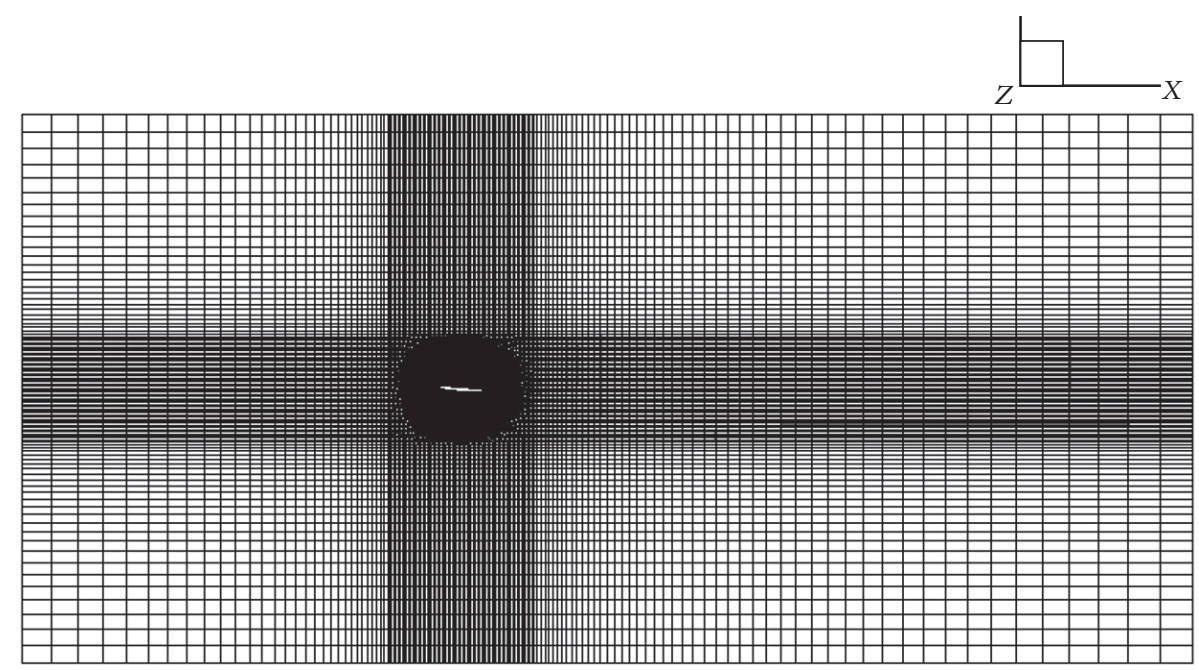

(a) The whole domain at plane $Z=0$

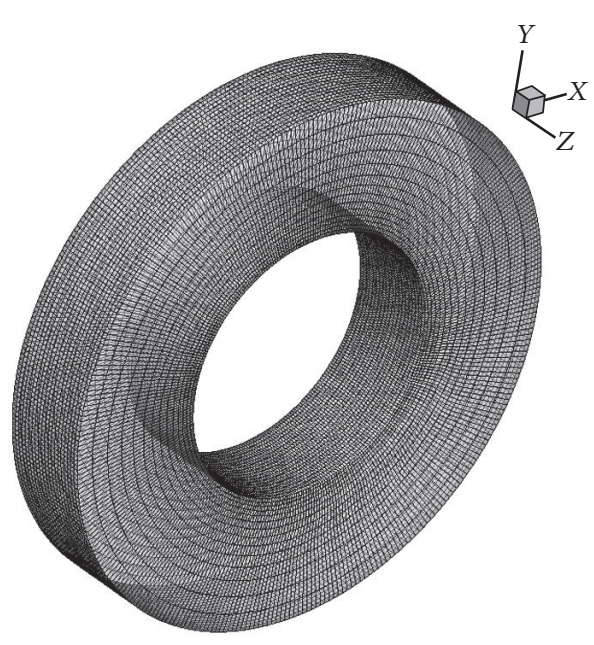

(b) The Deforming Zone

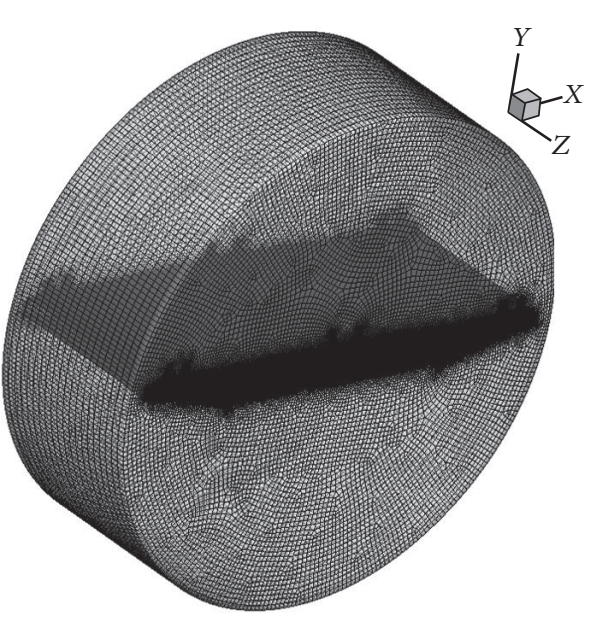

(c) The Rigidbody Zone

Figure 8: Mesh distributions of Case $\# 0$ at attack angle $+5^{\circ}$.

vertical damping, and stiffness parameters, and $\ddot{y}, \dot{y}, y$ are the vertical acceleration, speed, and displacement, respectively.

Similarly, in the system with a torsional freedom, the motion function is

$$
M_{\theta} \ddot{\theta}+C_{\theta} \dot{\theta}+k_{\theta} \theta=\frac{1}{2} \rho U^{2} B^{2} L \cdot C_{M}(t),
$$

where $C_{M}(t)$ is the coefficient of pitching moment; $M_{\theta}$ is the generalized mass of torsional freedom, $C_{\theta}$ and $k_{\theta}$ are the torsional damping and stiffness parameters, and $\ddot{\theta}, \dot{\theta}, \theta$ are the torsional acceleration, speed, and displacement, respectively.

In wind tunnel tests, the vertical and torsional displacement $y$ and $\theta$ are measured by lasers.

In order to verify the Hybrid-LES method adopted herein, the time-history of $C_{L}(t)$ obtained from numerical calculations is substituted into (2) to calculate inversely the time-history results of $y$ using Newmark- $\beta$ method. Likewise, the numerical time-history of $C_{M}(t)$ is substituted into (3) to calculate the time-history results of $\theta$. After that, the calculated results are compared with the experimental measured ones to determine the accuracy of Hybrid-LES method.

Figure 9 shows the comparison between the numerical and experimental results when the bridge deck is undergoing the maximum vertical and torsional VIVs, respectively. It shows that the numerical results are in good agreement with the experimental ones, indicating that the Hybrid-LES method is accurate and hence the flow field obtained by it is credible.

\section{VIV Mechanisms of Wide Flat Girders}

4.1. Occurrence Mechanisms of VIV. Vortex-induced vibration is a resonant phenomenon caused by the periodic vortex shedding from the structures. Consequently, the vortex structure and its shedding mode play decisive roles in determining whether VIV occurs or not. 


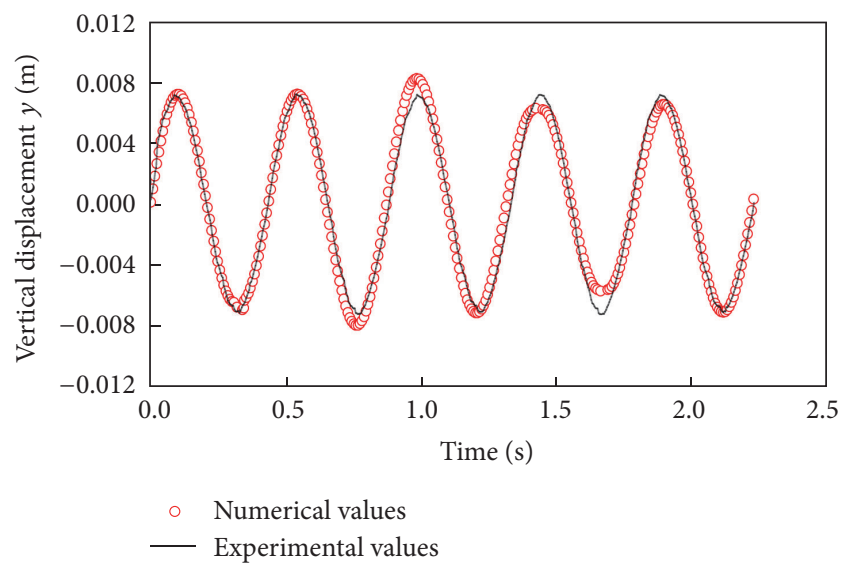

(a) Vertical displacement $y\left(U_{r}=2.092\right)$

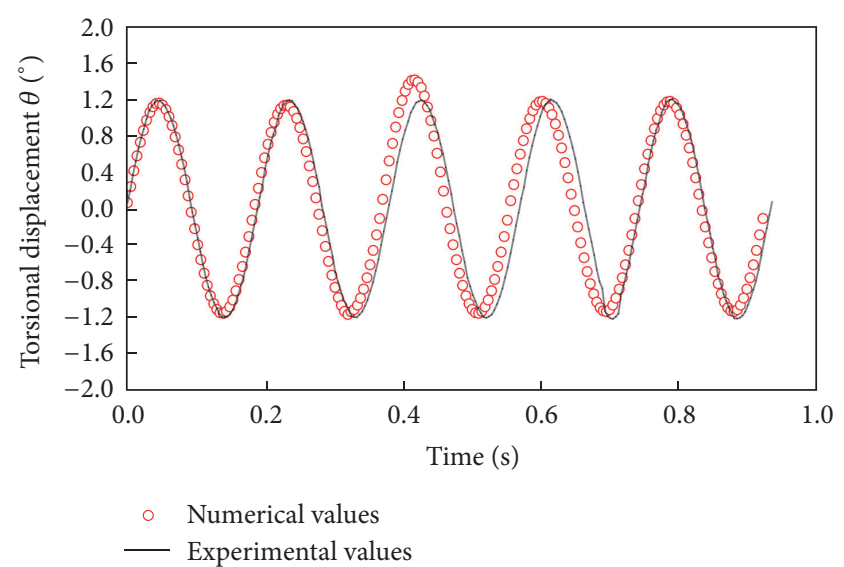

(b) Torsional displacement $\theta\left(U_{r}=2.532\right)$

FIGURE 9: Comparisons of vertical and torsional displacements obtained from Hybrid-LES and wind tunnel test.

On the definition of a vortex, there is no common agreement so far. Lugt [22] made a classical theory, "a vortex is the rotating motion of a magnitude of material particles around a common center." However, this definition is not Galilean invariant in the moving coordinates, and therefore it is not universally valid [23]. Currently, the dominant views on the definition of a vortex are based on the velocity gradient tensor, that is, to identify the vortexes in the flow field by identifying the core of them. The most commonly used criteria are Q-criterion [24], $\Delta$-criterion [25], and $\lambda_{2^{-}}$ criterion [26].

A vortex core is a concentration of vortexes. As the centrifugal force of the vortex motion, which reaches it minimum value at the vortex core, is balanced by the local pressure, the pressure here is the minimum on a plane [27]. Consequently, to identify a vortex core is to figure out where the minimum pressure locates.

Jeong and Hussain [26] took the gradient of the NavierStokes equations and obtained

$$
\frac{D S_{i j}}{D t}-v S_{i j, k k}+\Omega_{i k} \Omega_{k j}+S_{i k} S_{k j}=-\frac{1}{\rho} p_{i j},
$$

where $S_{i j}$ is strain tensor, defined as

$$
S_{i j}=\frac{1}{2}\left(\frac{\partial u_{i}}{\partial x_{j}}+\frac{\partial u_{j}}{\partial x_{i}}\right)
$$

$\Omega_{i j}$ is rotation tensor, defined as

$$
\Omega_{i j}=\frac{1}{2}\left(\frac{\partial u_{i}}{\partial x_{j}}-\frac{\partial u_{j}}{\partial x_{i}}\right) ;
$$

$p_{i j}$ is Hessian-pressure tensor.

To recognize the minimum local pressure, the term $p_{i j}$ is required to have two positive eigenvalues. And regarding (4), the first and second terms on the left side represent the unsteady irrotational strain effect and the viscous effect. If they are discarded, the only term $S^{2}+\Omega^{2}$ remains to determine the minimum local pressure. Consequently, a vortex core can be considered as the region where $S^{2}+\Omega^{2}$ has two negative eigenvalues. If $\lambda_{1}, \lambda_{2}, \lambda_{3}$ are assumed to be the eigenvalues of $S^{2}+\Omega^{2}$ and $\lambda_{1} \leq \lambda_{2} \leq \lambda_{3}$, the criterion of a vortex is $\lambda_{2} \leq 0$, and the smaller the $\lambda_{2}$, the stronger the vortex.

Figure 10 shows the vortex core structures of the bare deck and the preliminary designed completed deck (Case \#0) at attack angle $+5^{\circ}$.

For the bare deck, free vortexes are formed only on the upper surface due to the flow separation on the windward side. However, they are weak and unstable and hence rapidly decay when propagating downstream. Therefore, it is difficult to form sustained vortex shedding and they do not have the necessary conditions to generate a VIV.

Concerning Case \#0, strong vortexes are formed both on the upper and lower surfaces, most of which originate at the windward pedestrian guardrails where a strong separation occurs and the two inspection rails on the lower surface. These so-called nascent vortexes propagate downstream through different pathways to near-wake and interact with each other there, providing a continuous energy supply to the vortex shedding in the wake, which is necessary for the occurrence of VIV. Once the frequency of the vortex shedding (with enough intensity) is close to the natural frequency of the bridge, a vortex-induced vibration occurs-the resonant phenomenon of VIV.

4.2. Occurrence Mechanisms of Multi-Lock-in Regions. Figure 11 shows the power spectrum of $C_{L}(t)$ of Case \#0 under stationary conditions. It is interesting to know that the spectrum exhibits three dominant frequencies: $3.495 \mathrm{~Hz}$, $5.493 \mathrm{~Hz}$, and $7.241 \mathrm{~Hz}$, corresponding to the Strouhal numbers $\left(S_{t}\right) 0.0613,0.0962$, and 0.1269 , which are calculated as follows [28]:

$$
S_{t}=\frac{n_{s} D}{U},
$$

where $n_{s}$ is the vortex shedding frequency, $D$ is the height of the model, and $U$ is the incoming wind speed. The three 

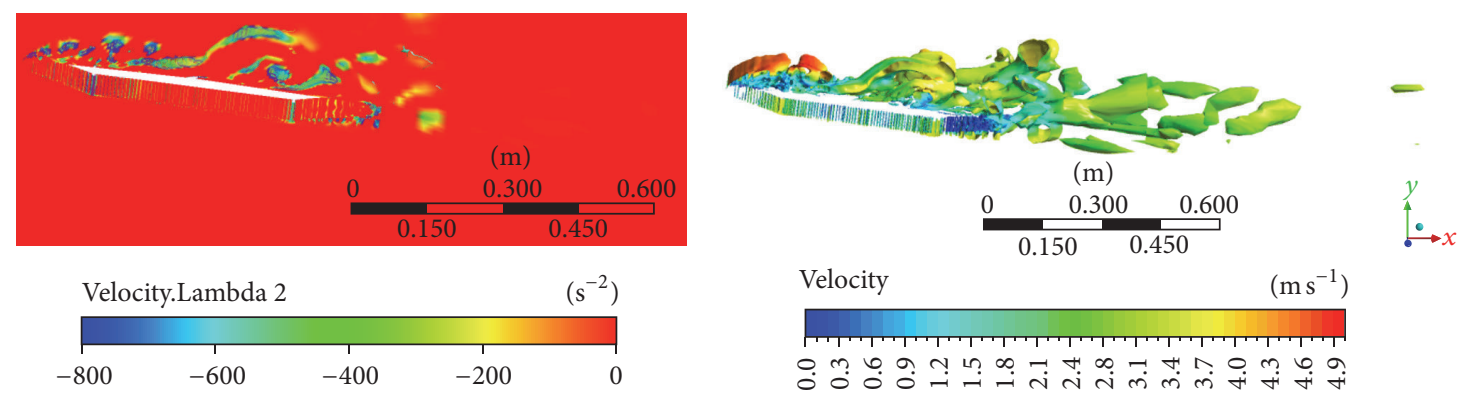

(a) The bare deck $\left(\alpha=+5^{\circ}, U_{r}=2.092\right)$
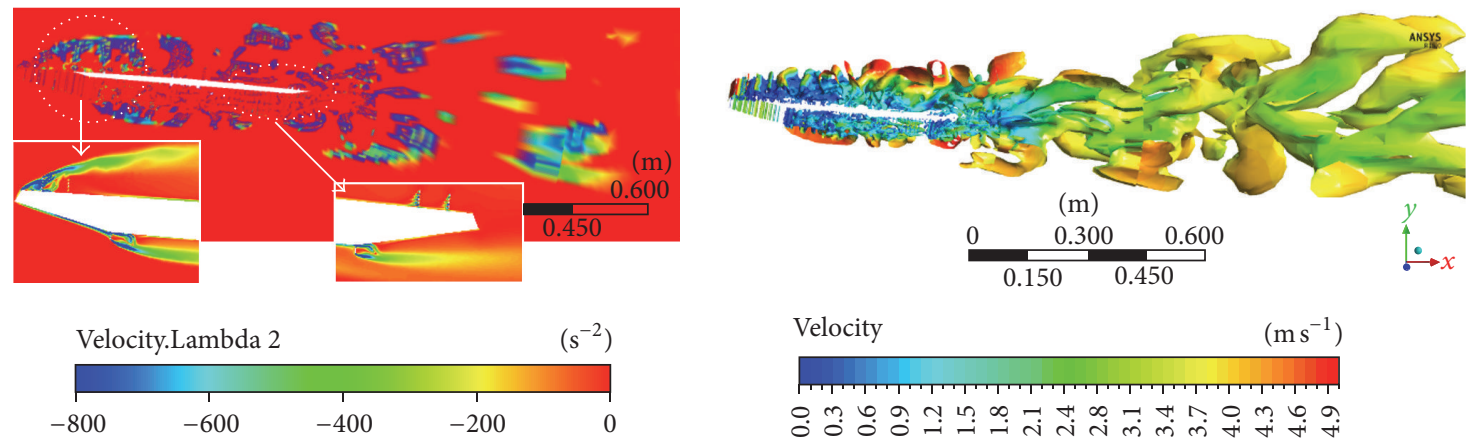

(b) The design completed deck (Case $\# 0, \alpha=+5^{\circ}, U_{r}=2.092$ )

FIGURE 10: Vortex core structures under stationary conditions. Left: contour map of $\lambda_{2}$; right: ISO surface of $\lambda_{2}=-10 \mathrm{~s}^{-2}$.

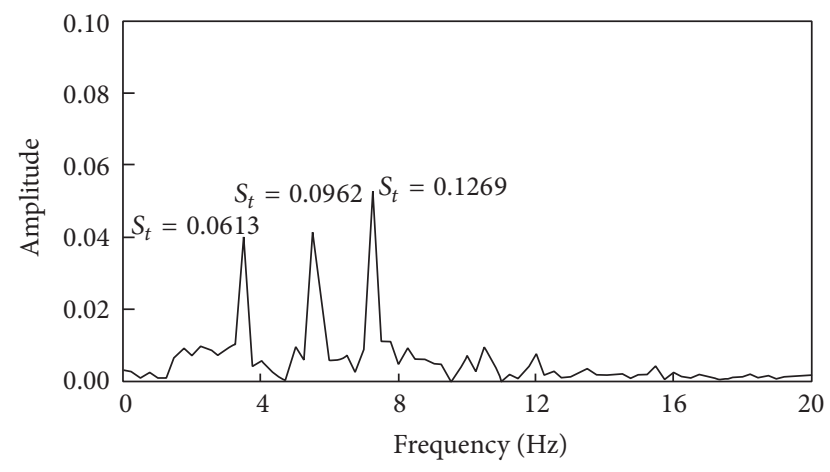

Figure 11: Power spectrum of the $C_{L}(t)$ of Case \#0 under stationary condition $\left(\alpha=+5^{\circ}, U_{r}=2.092\right)$.

dominant frequencies indicate that the vortex shedding gives rise to VIV in different ways, which ascribes to the three nascent vortexes shedding to near-wake through different pathways (see Figure 10(b)). Although the strengths of the vortex shedding are weak, it is reasonable that the potential VIVs will be controlled by them.

In order to further study some related characteristics of the vertical and torsional VIV responses, Figure 12 shows the relationships among the reduced wind speed, the vortex shedding frequency, the shedding strength, and the oscillation amplitude.

As for the wind speeds outside the lock-in regions, each spectrum has a band of noises which consists of more than one frequency, rather than one dominant frequency. While, within the lock-in regions, each spectrum has only one dominant frequency whose magnitude is significantly higher than those outside the lock-in regions and is positively correlated with oscillation amplitude.

Concerning the vertical VIV lock-in region of Case \#0 at attack angle $+5^{\circ}$, its initial stage starts at $U_{r}=1.068$; call it $\mathbf{V}_{\mathbf{1}}$ herein. The dominant frequency of $\mathbf{V}_{1}$ is $3.25 \mathrm{~Hz}$, which is not consistent with the natural vertical bending frequency of the bridge $(2.274 \mathrm{~Hz})$. However, when it increases to $U_{r}=1.376$, call it $\mathbf{V}_{\mathbf{2}}$ herein, the dominant frequency is identical to the natural vertical bending frequency and consistent thereafter in the lock-in region. Consequently, it is interesting to find that the vertical VIV lock-in region of Case \#0 is composed of two different stages. Considering that $\mathbf{V}_{1}$ agrees well with the predicted value of $S_{t}=0.1269$, while $\mathbf{V}_{2}$ agrees with $S_{t}=0.0613$, see Figure 12(a), the whole lock-in region can be divided into two parts: the main region (starts at $\mathbf{V}_{2}$ ) at higher wind speeds with larger amplitudes and the subregion (starts at $\mathbf{V}_{1}$ ) at lower wind speeds with smaller amplitudes.

For the torsional VIV lock-in region of Case $\# 0$ at attack angle $+3^{\circ}$, the subregion and main region separated from each other. The starting wind speed of subregion $\mathbf{T}_{1}\left(U_{r}=1.445\right)$ agrees well with the predicted value of $S_{t}=0.1269$, while the starting wind speed of main region $\mathbf{T}_{2}$ agrees with $S_{t}=$ 0.0962; see Figure 12(b).

As mentioned above, Case \#0 has three $S_{t}: 0.0613,0.0962$, and 0.1269 . And it can be summarized that the subregions and main-regions discussed above are controlled by two of the three $S_{t}$. Actually, the 3rd one also contributes but little (compared with the other two) to the motion of the bridge deck, which should ascribe to the different intensities of the three nascent vortexes when shedding to near-wake. 


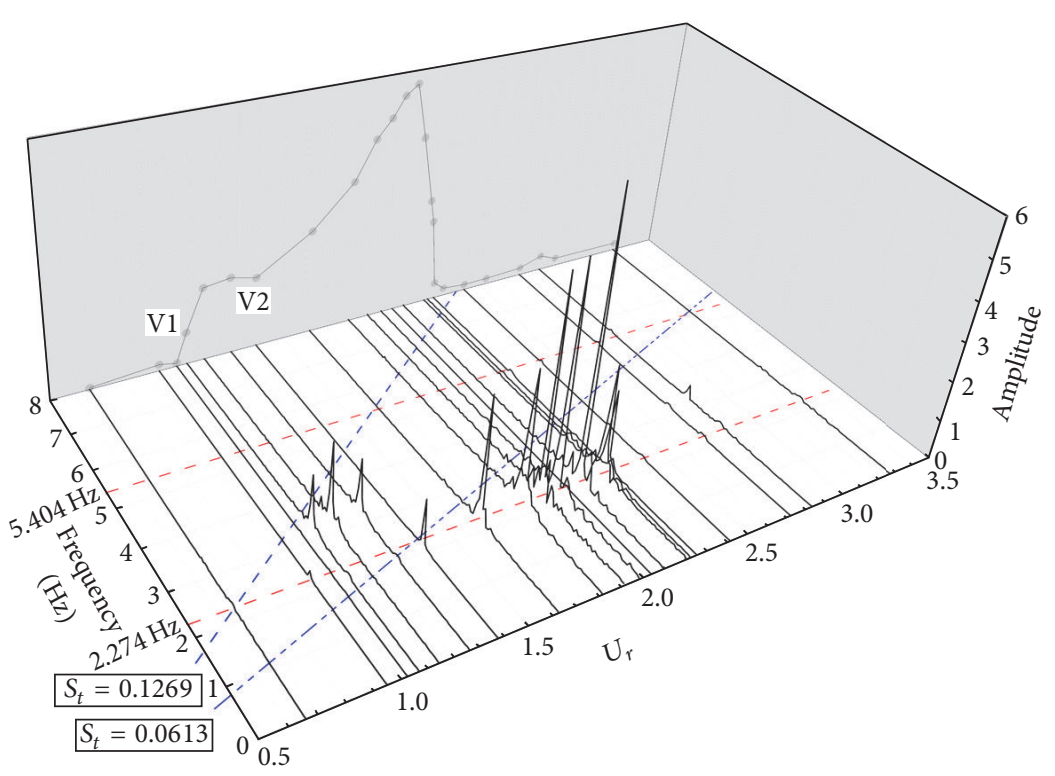

(a) Vertical oscillation (Case $\# 0, \alpha=+5^{\circ}$ )

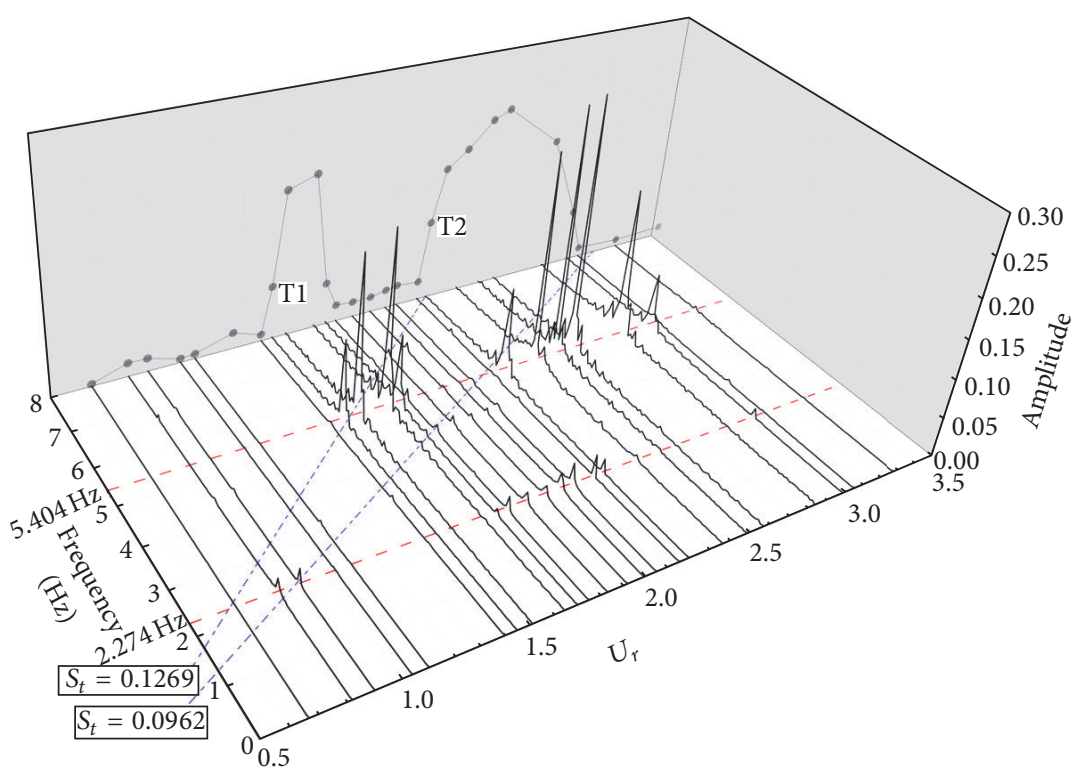

(b) Torsional oscillation (Case \#0, $\alpha=+3^{\circ}$ )

FIGURE 12: Relationships among the reduced wind speed, the vortex shedding frequency, the shedding strength, and the oscillation amplitude.

However, in this case they shed with approximately the same intensities, meaning that the three $S_{t}$ contribute equivalently to the oscillation. This is why the vertical VIV response of Case $\# 0$ at attack angle $+3^{\circ}$ has three different stages: the main region at $U_{r}=1.746 \sim 2.155$ and the other two VIV responses at $U_{r}=0.898$ and 1.269 (Figure 3(b)).

Extra attention should be paid to the differences of the relationship of main region and subregion between vertical and torsion VIVs. As discussed above, there is an obvious "gap" between the two regions of torsional VIV, while no such "gap" is observed for vertical VIV. One possible reason is that the Power Spectral Density (PSD) of the main region of vertical VIV is much higher than that of the subregion
(24.06 versus 1.314; see Figure 12(a)) and is consequently able to merge the subregion.

4.3. Flow Evolutions of VIV. In order to further study the mechanisms of vertical and torsional VIV on wide flat box girders, considering that the maximum amplitude of VIV can best reflect its essence, the whole processes when the bridge deck Case $\# 0$ is undergoing the maximum vertical and vertical VIVs are simulated using the Hybrid-LES method validated above. The evolution of vortex patterns and the feedback loop systems are analyzed based on numerical results. 
Figure 17(a) describes the vortex evolution pattern of vertical VIV. A strong flow separation occurs at the windward pedestrian guardrail, the majority of the airflow strips towards the top of the guardrails and generates a nascent vortex with strong intensity. As the bridge deck is wide enough, the nascent vortex impinges on the central separation guardrail when the bridge deck moves downwards, which is controlled by the inertial force, instead of shedding to near-wake directly. A new vortex (call it the secondary vortex) is formed due to the impingement and propagates downstream instead of the nascent vortex.

Concerning the small part of airflow deviating towards the lower surface caused by the blockage of the windward pedestrian guardrail during the separation, it interacts with the windward inspection rails and generates a nascent vortex which merges with the vortexes generated in the leeward inclined regions. Finally, the merging vortex meets the secondary vortex coming from the upper surface in nearwake and then alternately sheds downstream following " $2 S$ " mode. That is, when the oscillation reaches its maximum displacement on one side, a single vortex sheds to the opposite side and gives rise to a backswing of the bridge deck. Thus there are two single vortex sheds in one cycle, which is similar to the classic Karman Street [5]. The periodic vortex-induced force, which is generated by the regular vortex shedding,then makes the bridge deck to oscillation periodically in the vertical direction.

Figure 18(a) shows the vortex evolution pattern of torsional VIV. As mentioned above, the separation at the windward pedestrian guardrail generates two nascent vortexes. In the process that the bridge deck oscillates clockwise, that is, the first half cycle, the increase of effective attack angle results in a so rapid development of the nascent vortex on the upper surface that it becomes longer and stronger and covers the windward half of the upper surface. Meanwhile, the tail of the nascent vortex rapidly impinges on the central separation guardrail and generates a secondary vortex. As the bridge deck is still in the clockwise motion at this moment, the secondary vortex is therefore pushed to the trailing edge of the bridge and sheds to near-wake in the first half cycle. On the other hand, the increase of effective attack angle also results in a development of the nascent vortex on the lower surface, making it impinge on the middle wall of the lower surface. However, the newly generated secondary vortex is unstable due to the instability of its nascent vortex. Hence, the secondary vortex is absorbed by the vortexes generated in the leeward inclined regions.

In the process that the bridge deck oscillates anticlockwise, that is, the second half cycle, the decrease of effective attack angle results in the along-wind size increase while cross-wind size decreases to all the vortexes. The tail of the nascent vortex generated at the windward inspection rails connects with the head of the nascent vortex generated at the leeward inspection rail, providing an extra energy supply and promoting its shed to near-wake.

Now, pay attention back to the nascent vortex on the upper surface; it fails to reach near-wake in the first cycle but makes it in the first half of the next cycle. Consequently, the vortex shedding mode of torsional VIV is different from the
" $2 S$ " mode of vertical VIV. Considering that the secondary and nascent vortex on the upper surface shed alternately in two cycles while the lower vortex sheds periodically (shed once in a cycle), we call this type of vortex shedding " $4 / 2 \mathrm{~S}$ " mode.

Furthermore, the feedback loop systems between vortex shedding and the motion of bridge deck are different between vertical and torsional VIV. For vertical VIV, the windward and leeward vortexes are continuous and have roughly the same intensities and sizes, while those of torsional VIV have obvious boundaries and differences between different phases, which have been discussed above.

\section{Control of VIV on Wide Flat Box Girders}

\subsection{A New Approach}

5.1.1. Theoretical Background of Guardrails on Bridges. Guardrails are important members of subsidiary structures on bridges; they are divided into anticollision guardrails and pedestrian guardrails. The anticollision guardrails are mainly mounted to prevent vehicle collisions; their resistance capability is strictly specified by specifications concerned, while the pedestrian guardrails are usually mounted near the edge of the bridge deck, mainly used to prevent pedestrians on the bridge from falling off.

In wind tunnel tests, the scaled model of guardrails is often engraved by automachine, as the models are so small that their prototype cannot be reproduced considering every detail. After ensuring that the model is able to describe the fundamental features of the prototype, some simplifications are introduced with respect to the limitation of the machine. Figure 13 provides a close-up view of the pedestrian guardrail structures of Case \#0.

As is shown in Figure 13, the guardrail is simplified as horizontal bars and vertical posts. For convenience, terminology $d$ is introduced to express the depth of guardrail; $H_{0}$ is the height of guardrail; $H_{1}$ is the height of horizontal bar; $H_{2}$ is the height between two horizontal bars; $N_{\mathrm{HB}}$ is the number of horizontal bars; $W_{0}$ is the width between two vertical posts; $W_{1}$ is the width of vertical post. And $\varphi=A_{\text {void }} / A$ is the ventilation rate, where $A_{\text {void }}$ is the void area and $A=H_{0}\left(W_{0}+\right.$ $\left.2 W_{1}\right)$ is the whole area of the guardrail projected to a $2 \mathrm{D}$ plane in elevation.

5.1.2. Control Schemes. It is well known that the guardrails have a relevant blockage effect to the flow passing over the upper surface of the bridge deck [10]. In the present study, discussions in Sections 4.1 and 4.3 indicate that the flow pattern near the leading edge is greatly influenced by the windward pedestrian guardrails, and the strong flow separation occurring here is of vital importance in the occurrence and evolution of VIV. Therefore, it is feasible to suppress VIV responses by weakening the flow separation there. Considering that the nose of the bridge deck is aerodynamic efficient and the windward pedestrian guardrails give rise to strong flow separation [8], we have introduced (after several trials) some minor modifications to the basic structure of the 


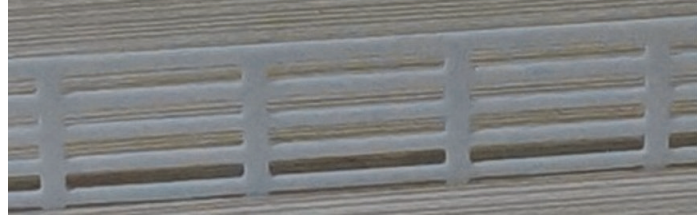

(a) Wind tunnel testing model

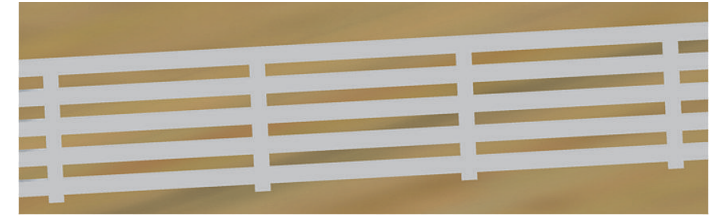

(b) Numerical model in CFD simulations

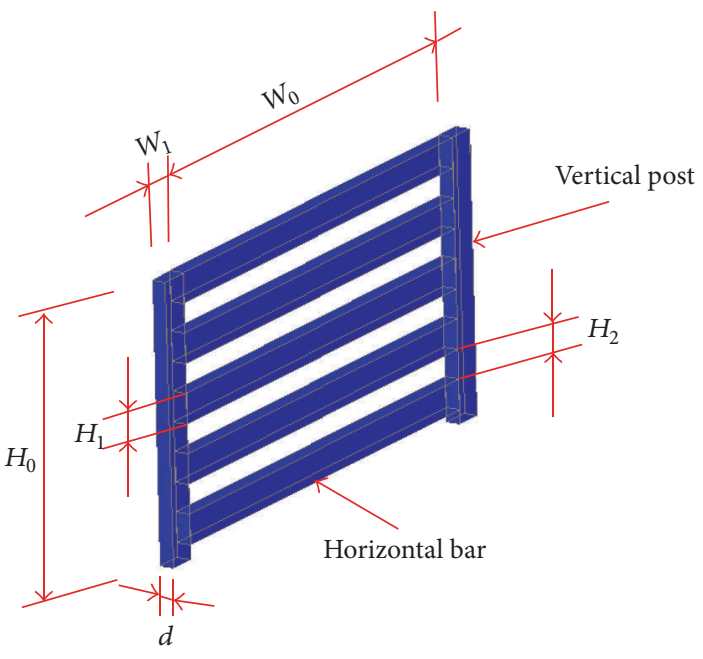

(c) Definitions of terminologies

FIgURE 13: A close-up view of pedestrian guardrail structures (Case \#0).

pedestrian guardrails, aiming to make it more aerodynamic friendly.

In order not to cause extra efforts in making molds of the pedestrian guardrails, we reduce the number of horizontal bars $\left(N_{\mathrm{HB}}\right)$ and revise the height between them $\left(\mathrm{H}_{2}\right)$ to obtain higher ventilation rate $\varphi$; thus they are supposed to cause less blockage effect to the flow.

As specified by several Chinese specifications [29, 30], the prototype size of $H_{0}$ must not be lower than $1100 \mathrm{~mm}$ and $H_{2}$ must not exceed $240 \mathrm{~mm}$. It is calculated that the minimum $N_{\mathrm{HB}}$ is 3; otherwise $\mathrm{H}_{2}$ (at prototype size) could be higher than $240 \mathrm{~mm}$. Therefore, we have introduced two control schemes (named Case \#1 and Case \#2) whose $N_{\mathrm{HB}}$ is 4 and 3, respectively. And they have the ventilation rate $\varphi$ of $45.8 \%$ and $59.8 \%$, which is $28.7 \%$ and $68.0 \%$ larger than that of the preliminary designed one $(35.6 \%$, Case \#0). Details of the pedestrian guardrails of Cases \#0,1, and 2 have been presented in Table 2.

The control efficiencies of the proposed schemes are studied by wind tunnel tests and analyzed in the next section.

5.2. Control Efficiencies. Comparisons of the RMS of displacement among Cases \#0, 1, and 2 are shown in Figures 14 and 15.

For Case \#1 at attack angle $+5^{\circ}$, the vertical oscillation amplitudes are close to zero at $U_{r}=1.457 \sim 1.709$, which are included in the lock-in region of Case \#0, separating the VIV responses into two lock-in regions: the main region at higher wind speeds $U_{r}=1.709 \sim 2.249$ and the subregion at lower wind speeds $U_{r}=1.005 \sim 1.457$. The maximum vertical amplitude is $20 \%$ lower than that of Case \#0. As for torsional VIV, the maximum amplitude of Case \#1 is $24.2 \%$ lower than that of Case \#0.

For Case $\# 1$ at attack angle $+3^{\circ}$, the lock-in region of vertical VIV is approximately the same with the main lockin region of Case \#0, with the disappearance of VIV at lower wind speeds, and the maximum amplitude calls for an $80 \%$ decrease. Furthermore, the torsional oscillation amplitudes are close to zero at $U_{r}=2.199 \sim 2.984$ where the main lockregion of Case \#0 locates. The decrease of maximum torsional amplitude from Case \#0 to Case \#1 in the sub-lock-in region is $17.3 \%$.

Concerning Case \#2 at attack angle $+5^{\circ}$, it has a consistent efficiency with Case \#1 in reducing the lock-in region of vertical VIV, but it suppresses the amplitude better as its maximum vertical amplitude is $62.4 \%$ lower than that of Case $\# 0$. As for torsional VIV, the maximum amplitude of Case \#2 is $39.2 \%$ lower than that of Case \#0.

Regarding Case $\# 0$ at attack angle $+3^{\circ}$, the vertical and torsional oscillation amplitudes are close to zero at every testing wind speed, indicating that VIV is completely suppressed.

Consequently, it can be summarized that the vertical and torsional VIVs of wide flat box girders can be suppressed by increasing the ventilation rate of pedestrian guardrails, and the control efficiencies depend on the attack angle.

5.3. Controlling Mechanisms. Literatures [9, 12, 16, 31] focused their attention on the flow patterns when explaining the 
TABLE 2: Model parameters of the pedestrian guardrails tested (model scale 1:60 [cm]).

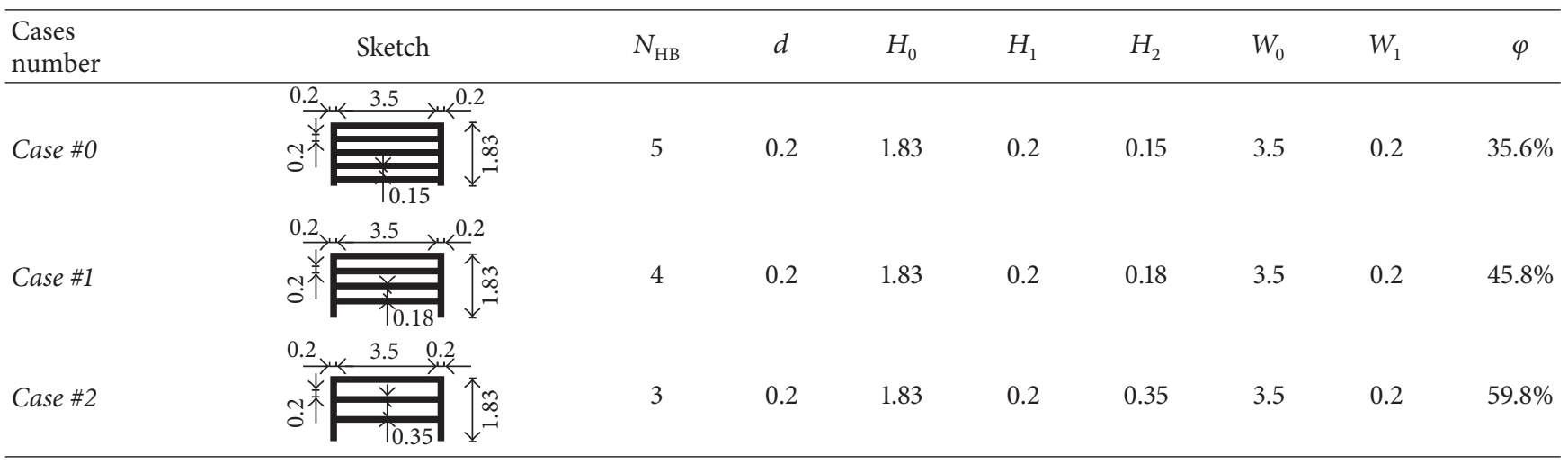

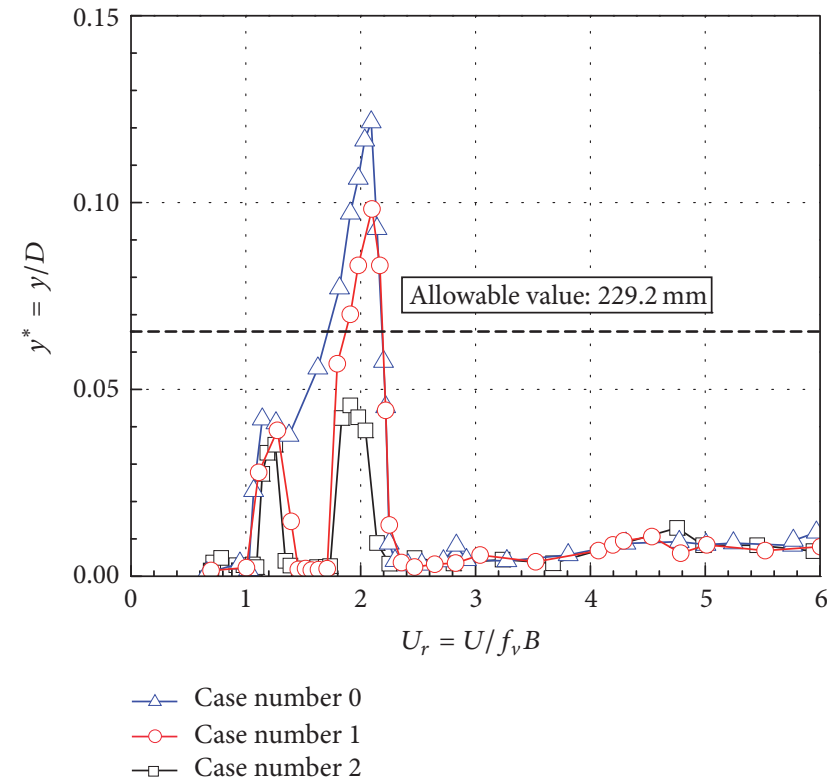

(a) $\alpha=+5^{\circ}$

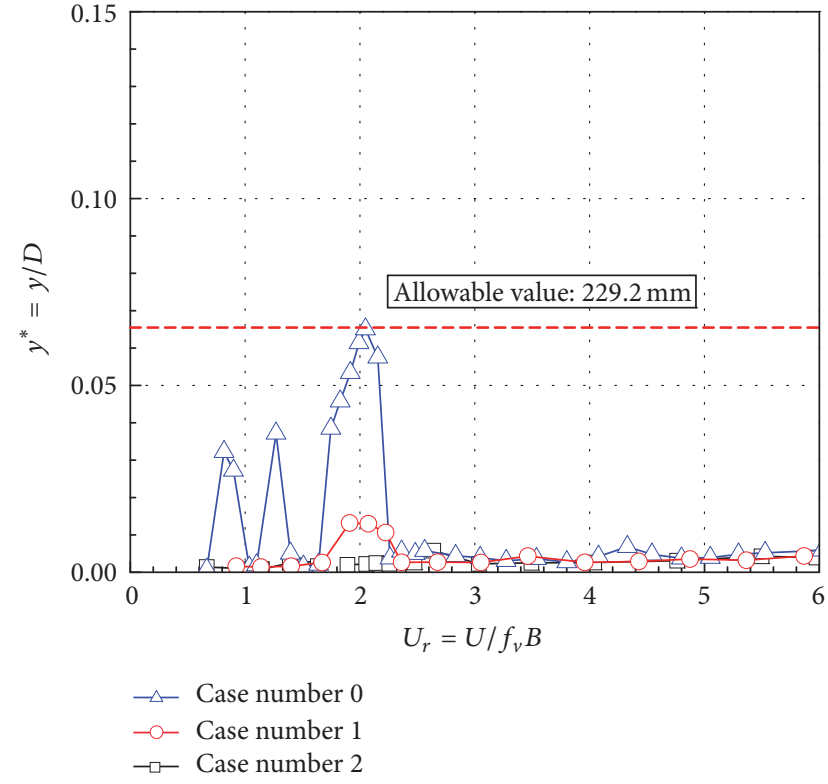

(b) $\alpha=+3^{\circ}$

FIGURE 14: Comparisons of the RMS vertical displacement $y$ among Cases \#0, 1, and 2.

controlling mechanisms of VIV. To understand both conceptually and sensuously why and how VIV is suppressed, the present study will firstly introduce a mathematical model and then the flow visualization of VIV.

5.3.1. Mathematical Model. As the oscillation of VIV is a kind of simple harmonic motion, thus the lift force $C_{L}(t)$ in $(2)$ can be written as follows [32]:

$$
C_{L}(t)=C_{L} \sin \left(\omega_{s} t+\phi\right)
$$

where $\omega_{s}$ is the circular frequency of vortex shedding and $\phi$ is the phase angle. Then (2) can be rewritten as

$$
m \ddot{y}+C \dot{y}+k_{y} y=\frac{1}{2} \rho U^{2} B L \cdot C_{L} \sin \left(\omega_{s} t+\phi\right) .
$$

Assuming that the motion of VIV is in phase with the lift force $(\phi=0)$, and the modal damping $C$ is negligible, which is feasible in a qualitative analysis [32], then the general solution of (9) is

$$
\begin{aligned}
y(t)= & A \cos \omega t+B \sin \omega t \\
& +\frac{F_{L}}{k_{y}}\left[\frac{1}{1-\left(\omega_{s} / \omega\right)^{2}}\right] \sin \omega_{s} t,
\end{aligned}
$$

where $\omega$ is the circular natural frequency of the section model and $F_{L}=(1 / 2) \rho U^{2} B L \cdot C_{L}$ is the lift force. Considering the initial conditions that $y(0)=\dot{y}(0)=0$, then

$$
\begin{aligned}
& A=0, \\
& B=-\frac{F_{L} \beta}{k_{y}}\left[\frac{1}{1-\beta^{2}}\right] .
\end{aligned}
$$




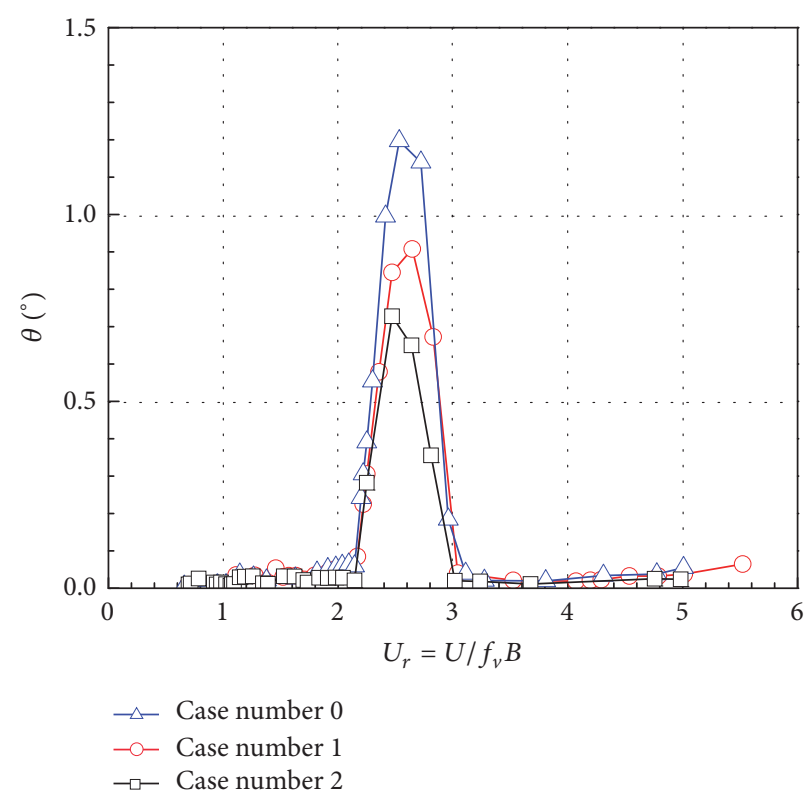

(a) $\alpha=+5^{\circ}$

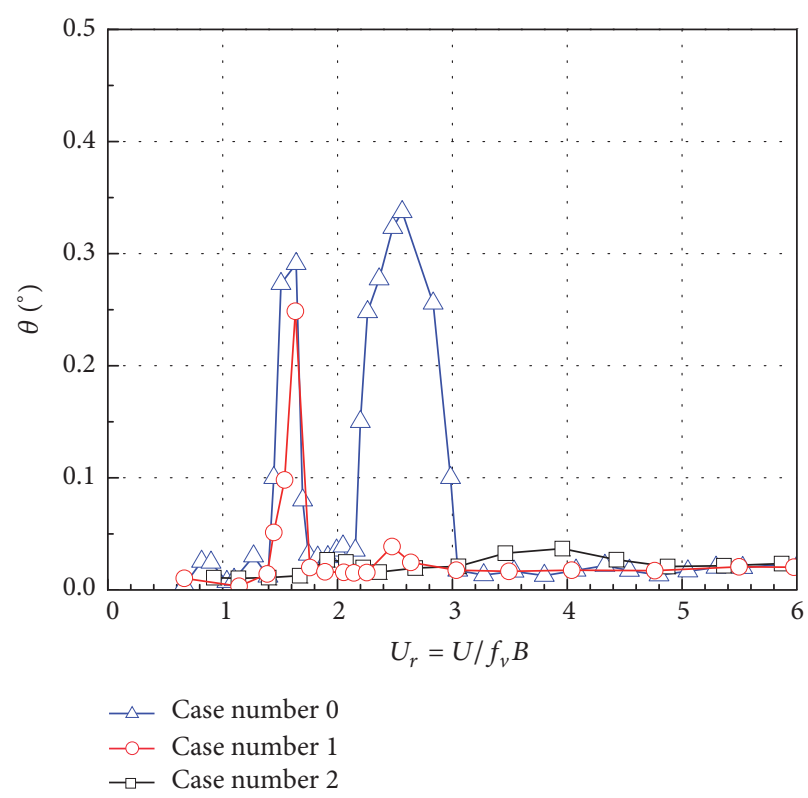

(b) $\alpha=+3^{\circ}$

Figure 15: Comparisons of the RMS torsional displacement $\theta$ among Cases \#0, 1, and 2.

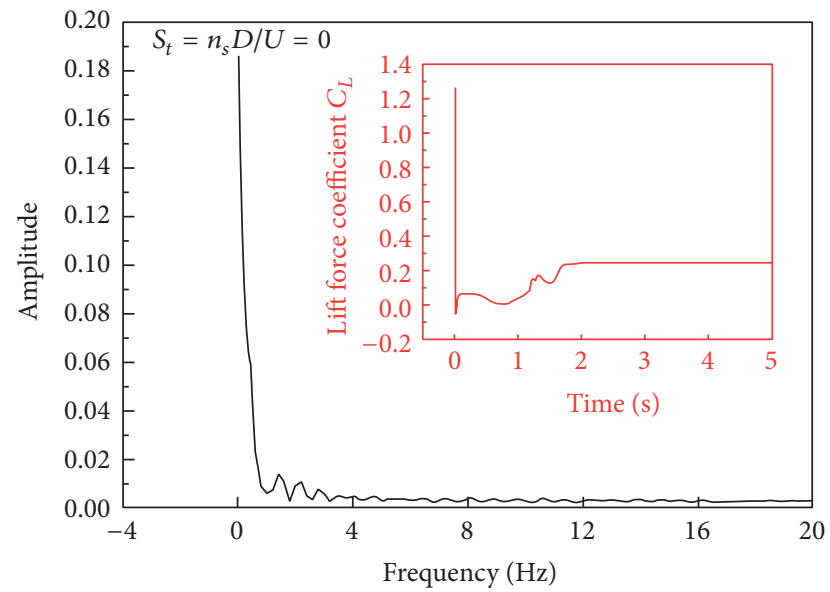

Figure 16: Power spectrum and time-history of the $C_{L}(t)$ of Case \#2 under stationary condition $\left(\alpha=+3^{\circ}, U_{r}=1.094\right)$.

Thus

$$
y(t)=\frac{F_{L}}{k_{y}}\left[\frac{1}{1-\beta^{2}}\right]\left(\sin \omega_{s} t-\beta \sin \omega t\right),
$$

where $\beta=\omega_{s} / \omega$ for convenience.

We choose Case \#2, whose vertical and torsional oscillation amplitudes are close to zero at every testing wind speed at attack angle $\alpha=+3^{\circ}$, as an example of completely suppressed VIVs. Figure 16 shows the power spectrum of $C_{L}(t)$ under stationary conditions. The calculated wind speed $U_{r}=1.094$, where Case \#2 undergoes its maximum vertical VIV at attack angle $\alpha=+5^{\circ}$, is chosen for a convincing conclusion.

It can be seen that, the dominant frequency is $0 \mathrm{~Hz}$, that is, vortex frequency $n_{s}=0$, indicating that the periodic vortex shedding is eliminated by the control schemes. Considering the circular frequency of vortex shedding $\omega_{s}=2 \pi n_{s}=0$, and the circular frequency of the section model $\omega=2 \pi f_{v}=$ $13.936 \mathrm{~Hz}\left(f_{v}\right.$ have been listed in Table 1$)$, then $\beta=\omega_{s} / \omega=$ 0 . Therefore, $y(t)=0$ according to (12), indicating that the dynamic displacement caused by VIV is negligible-that is why VIV is completely suppressed.

5.3.2. Flow Visualization. Specification terms [14] do not obligate the avoidance of VIV, because the vortex shedding around bridge decks cannot be completely eliminated at larger attack angles. Bridges are considered safe as long as the oscillation amplitude of VIV does not exceed the allowable value. In the present study, when the attack angle $\alpha$ is as large as $+5^{\circ}$, the proposed approach has successfully reduced both vertical and torsional oscillation amplitudes to meet the specification requirements.

To understand sensuously how VIV is suppressed by the proposed approach, vortex patterns and evolutions are presented and compared in this section. In the same way as the simulation of Case \#0 in Section 4.3, the whole processes when Cases \#1 and 2 are undergoing their maximum vertical and torsional VIVs are simulated, respectively. The comparisons of vortex evolutions of vertical VIVs are shown in Figure 17, and those of torsional VIVs are shown in Figure 18.

It can be seen from Figure 17 that, with the increase in ventilation rate comparing Cases \#1 and 2 with Case \#0, the flow separation at the windward pedestrian guardrails slows down and, consequently, the nascent vortex on the upper surface is weakened. Moreover, some airflow of the nascent vortex crosses through the clearances of the pedestrian guardrails instead of stripping towards its top but is obstructed and dissipated by the following anticollision 

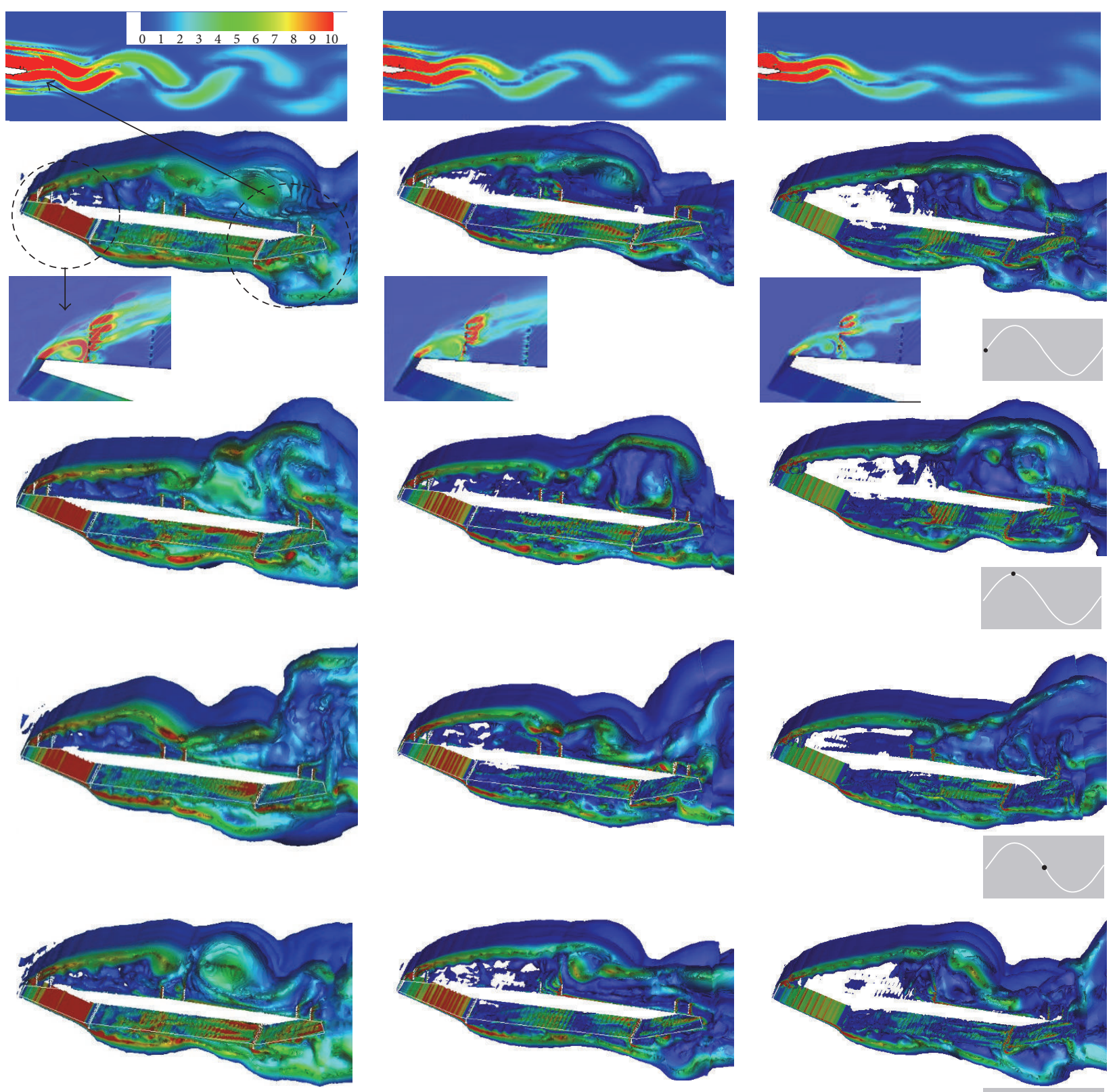

(a) Case $\# 0\left(U_{r}=2.092, y=0.122 D\right)$

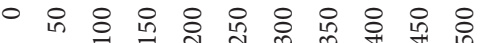

(b) Case \#1 $\left(U_{r}=2.098, y=0.099 D\right)$
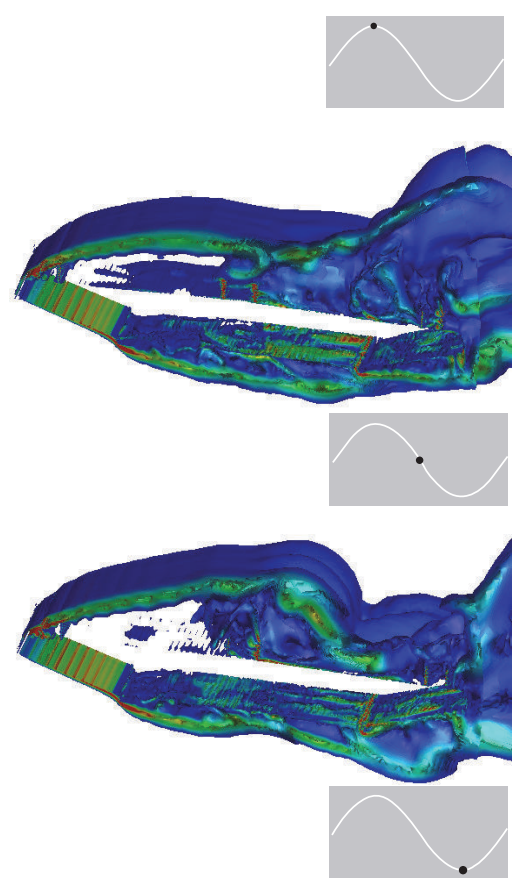

(c) Case \#2 $\left(U_{r}=1.904, y=0.046 D\right)$

FIGURE 17: Instantaneous vorticity contours in a periodic vertical VIV $\left(\alpha=+5^{\circ}\right)$.

guardrails. Considering these two reasons above, the nascent vortex shedding to near-wake is greatly reduced both in intensity and size, and its structure begins to be unstable. It is evident that the nascent vortex of Case $\# 1$ on the upper surface can hardly generate a secondary vortex during its impinging on the central separation guardrail. And furthermore, the majority of the nascent vortex of Case \#2 transforms into turbulent flows or smaller $3 \mathrm{D}$ structures due to the impinging.
Concerning the small part of airflow moving towards the lower surface during the separation, it is reduced as the upper surface becomes more ventilative by the increase in the ventilation rate of the pedestrian guardrail; hence the nascent vortexes on the lower surface are weakened as well for Cases $\# 1$ and 2.

Considering these two aspects above, the upper and lower vortexes both fail to get rid of the motion of the bridge deck 

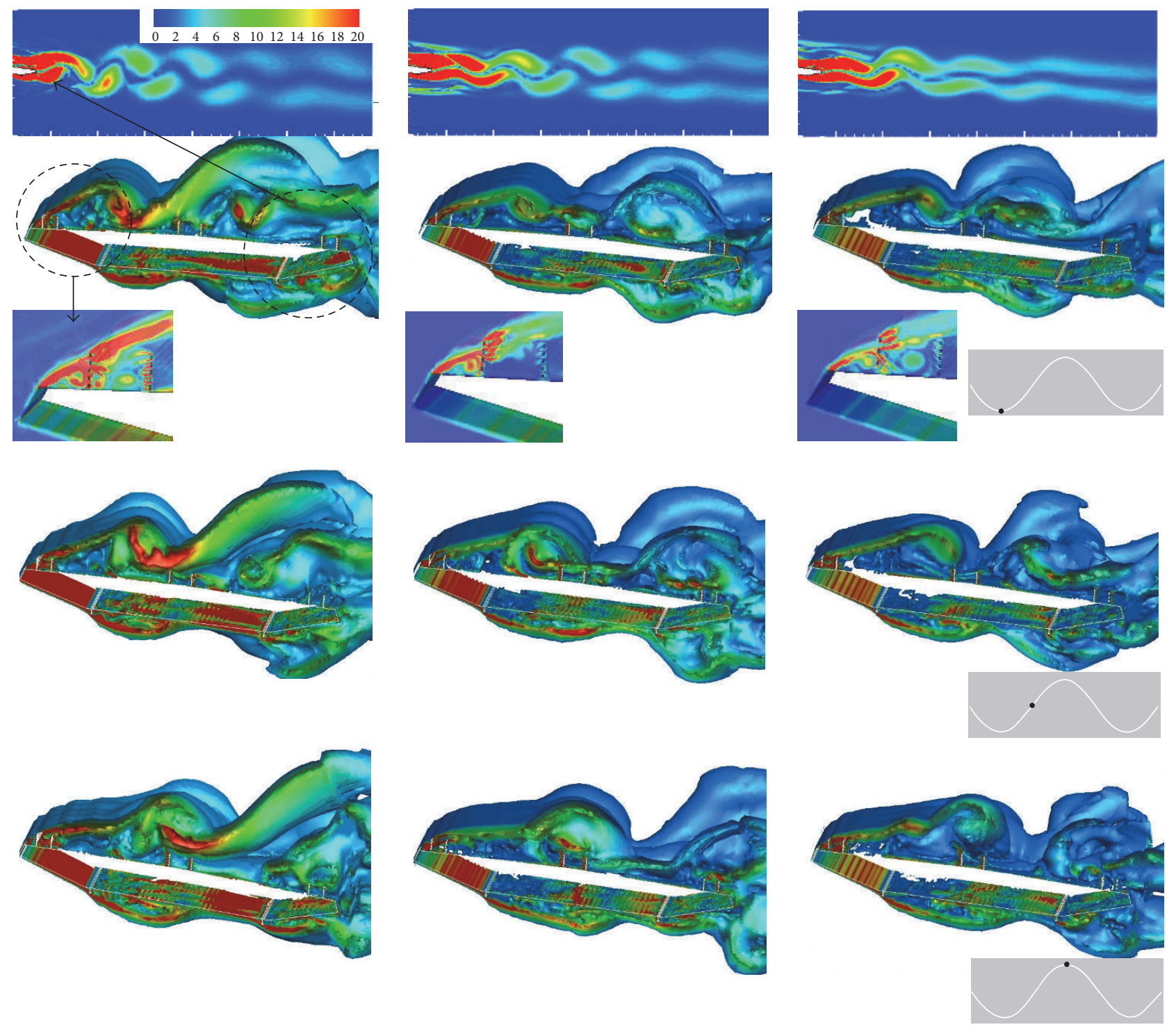

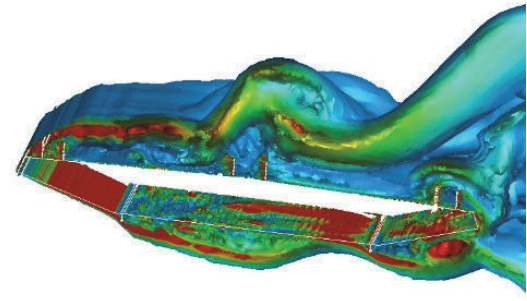

(a) Case \#0 $\left(U_{r}=2.532, \theta=1.197^{\circ}\right)$

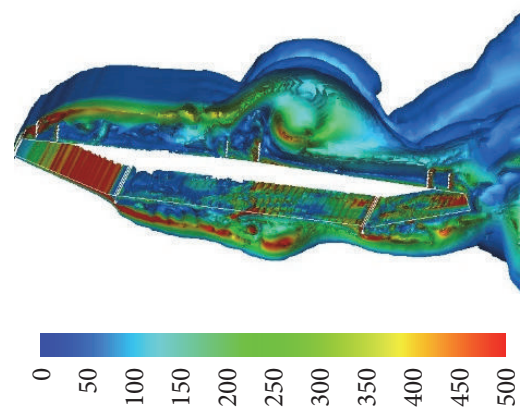

(b) Case \#1 $\left(U_{r}=2.645, \theta=0.908^{\circ}\right)$

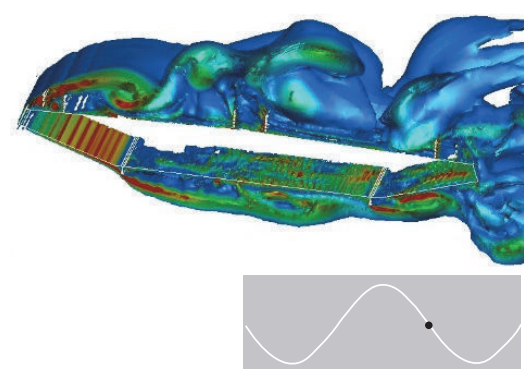

(c) Case \#2 $\left(U_{r}=2.469, \theta=0.728^{\circ}\right)$

FIGURE 18: Instantaneous vorticity contours in a periodic torsional VIV $\left(\alpha=+5^{\circ}\right)$.

in near-wake. Instead, they firstly swing "fish-like," controlled by the motion of the bridge deck, and succeed to shed only if they are far enough from the bridge deck. The term "shedding starting point" is applied herein to define where the shedding starts. As this point becomes more hysteretic comparing Case
\#1 with Case \#0, the vortex-induced force has less feedback on the motion of the bridge deck. And synchronously, the intensity and cross-wind size of the " $2 S$ " vortex shedding are decreased; thus Case \#1 acts well in controlling vertical VIV. Considering that the "shedding starting point" of Case \#2 is 
more hysteretic as the intensity and cross-wind size decrease further, Case \#2 shows better control efficiency.

Regarding the mechanism of Cases \# 1 and 2 in controlling torsional VIV comparing Figures 18(a), 18(b), and 18(c), similar differences are observed to those found in vertical VIV, and the control should also be ascribed to the weakening of vortex shedding's energy supply and the vortex-induced force's feedback to the motion of bridge deck.

5.4. Advantages of the Approach. To control wind-induced vibrations, three kinds of countermeasures had been proposed in bridge engineering: the aerodynamic measures, the structural measures, and the mechanical measures [14]. A brief introduction is as follows.

(i) Aerodynamic measures: this means changing fluid field through shape-modifications or additional appendages, so as to reduce wind-induced forces [14]. Shape-modifications include reshaping of the girder and adding central slots, but they both demand the restart of the overall designing work. Additional appendages include guide vanes, suppressing board, and central stabilizer. They will not only cause extra mass and financial costs to the bridge, but also affect the beauty of bridge deck.

(ii) Structural measures: this means increasing the overall stiffness of the structure by changing the force form and dynamics [14]. It demands a redesign of the overall bridge and always results in a significant increase in the amount of material used. Therefore, a lot of efforts and financial costs will be added.

(iii) Mechanical measures: this means increasing the structural damping through tuned mass dampers (TMDs) [14]. They belong to kind of remedial measures in case that VIVs are observed when the bridge has been put into use. The traffic has to be limited or closed during the installations of the TMDs, which may cause adverse social impacts concerning public travels. In addition, extra costs are demanded.

Encountering these situations above, the present approach aims at controlling VIVs by increasing ventilation rate of the pedestrian guardrails. The only differences between Cases \#1 and 2 and the original bridge deck Case $\# 0$ are the number of horizontal bars on the pedestrian guardrails and the height between them. Therefore, neither extra mass nor financial costs will be added. Moreover, the modifications are so minor compared with other measures that the present approach is more simple and feasible in operation than others.

\section{Conclusions}

(1) The bare deck of a wide flat box girder is streamlinedlike and therefore no VIV is recorded due to the lack of vortexes energy supply. However, in the case that the subsidiary structures are designed inappropriately, the wide flat box girder can undergo vertical and torsional VIVs with multi-lock-in regions. However, the subsidiary members have not been paid equal attention as the basic deck in the past designs. Therefore, all the subsidiary members must be designed specifically.

(2) The occurrence of VIV should ascribe to the three groups of nascent vortexes originating at the windward pedestrian guardrails and the two inspection rails. They shed to near-wake through different pathways with different frequencies, corresponding to three Strouhal numbers $\left(S_{t}\right)$. On condition that one of them has enough intensify and sheds with the frequency close to one of the natural frequencies of the bridge, VIV occurs. In the case that more than one of them have the frequencies close to the natural frequencies, which indicates that the VIV is controlled by two or three $S_{t}$, the multi-lock-in regions will be formed.

(3) A wide flat box girder can undergo VIVs at very low wind speeds, in a form of multi-lock-in regions. However, little attention was paid to quite low wind speeds in wind tunnel tests. Therefore, smaller loading steps are required for the dynamic tests at low wind speeds to avoid potential threats.

(4) The vortex shedding mode of vertical VIV on a wide flat box girder is " $2 \mathrm{~S}$ " mode, as the secondary vortex on the upper surface and the merging vortex on the lower surface alternately shed downstream, while, in a torsional VIV, the secondary and nascent vortex on the upper surface shed alternately in two coterminous cycles while the merging vortex on the lower surface sheds periodically, which is different from any other known ones and can be defined as " $4 / 2$ S" mode.

(5) Without extra expenses and dissatisfied impressions to the original designing bridge deck, the presented approach is more simple and feasible than other control schemes. By increasing ventilation rate of the pedestrian guardrails, it shows significant efficiencies in suppressing VIV on a wide flat box girder. Therefore, those kinds of guardrails with larger ventilation rate should be considered as priorities for the preliminary designs for new bridges, under the premise that the specification requirements have been met.

(6) The control mechanisms of the presented approach mainly ascribe to the weakening of the windward flow separation and hence the decrease of vortex shedding's energy supply and the vortex-induced force's feedback to the motion of bridge deck.

\section{Conflicts of Interest}

The authors declare that there are no conflicts of interest regarding the publication of this paper. 


\section{Acknowledgments}

This study is financially supported by the National Natural Science Foundation of China (NSFC) under Grants nos. 51578098 and 51608074.

\section{References}

[1] F. Y. Xu, W. Ding, J. Feng, and Z. Zhang, "Development and prospect of study on vortex-induced vibration of long-span bridges," Journal of Vibration and Shock, vol. 29, no. 10, pp. 4049, 2010.

[2] P. W. Bearman, "Vortex shedding from oscillating bluff bodies," Annual Review of Fluid Mechanics, vol. 16, no. 1, pp. 195-222, 1984.

[3] R. D. Gabbai and H. Benaroya, "An overview of modeling and experiments of vortex-induced vibration of circular cylinders," Journal of Sound and Vibration, vol. 282, no. 3-5, pp. 575-616, 2005.

[4] T. Sarpkaya, "A critical review of the intrinsic nature of vortexinduced vibrations," Journal of Fluids and Structures, vol. 19, no. 4, pp. 389-447, 2004.

[5] C. H. K. Williamson and R. Govardhan, "Vortex-induced vibrations," Annual Review of Fluid Mechanics, vol. 36, pp. 413$455,2004$.

[6] Z. Q. Chen, Wind-Induced Vibration, Stability and Control of Engineering Structures, Science Press, Beijing, China, 2013.

[7] Y. J. Ge, Wind Resistance of Long Span Suspension Bridges, China Communications Press, Beijing, China, 2011.

[8] L. L. Zhang, B. Wu, Y. Yang et al., "Effects of subsidiary members and deck surface roughness on the coefficients of static forces on a flat box girder," Journal of Experiments in Fluid Mechanics, vol. 30, no. 1, pp. 74-80, 2016.

[9] A. Larsen and A. Wall, "Shaping of bridge box girders to avoid vortex shedding response," Journal of Wind Engineering and Industrial Aerodynamics, vol. 104-106, pp. 159-165, 2012.

[10] L. Bruno and G. Mancini, "Importance of deck details in bridge aerodynamics," Structural Engineering International, vol. 12, no. 4, pp. 289-294, 2002.

[11] F. Nagao, H. Utsunomiya, E. Yoshioka, A. Ikeuchi, and H. Kobayashi, "Effects of handrails on separated shear flow and vortex-induced oscillation," Journal of Wind Engineering and Industrial Aerodynamics, vol. 69-71, pp. 819-827, 1997.

[12] M. W. Sarwar and T. Ishihara, "Numerical study on suppression of vortex-induced vibrations of box girder bridge section by aerodynamic countermeasures," Journal of Wind Engineering and Industrial Aerodynamics, vol. 98, no. 12, pp. 701-711, 2010.

[13] S. Laima, Investigation of Vortex-Induced Vibrations of TwinBox Girder of Long-Span Suspension Bridges, Harbin Institute of Technology, Harbin, China, 2013.

[14] JTG/T D60-01-2004, Wind-Resistant Design Specification for Highway Bridges, China Communications Press, Beijing, China, 2010.

[15] L. L. Huang, H. Liao, B. Wang, and Y. Li, "Numerical simulation for aerodynamic derivatives of bridge deck," Simulation Modelling Practice and Theory, vol. 17, no. 4, pp. 719-729, 2009.

[16] S. Laima, H. Li, W. Chen, and F. Li, "Investigation and control of vortex-induced vibration of twin box girders," Journal of Fluids and Structures, vol. 39, no. 5, pp. 205-221, 2013.

[17] M. R. Gharib, Vortex-Induced Vibration Absence of Lock in and Fluid Force Deduction, California Institute of Technology, Pasadena, Calif, USA, 1999.
[18] H. Li, W.-L. Chen, F. Xu, F.-C. Li, and J.-P. Ou, "A numerical and experimental hybrid approach for the investigation of aerodynamic forces on stay cables suffering from rain-wind induced vibration," Journal of Fluids and Structures, vol. 26, no. 7-8, pp. 1195-1215, 2010.

[19] A. R. Chen and H. L. Ai, Computational Bridge AerodynamicsLarge Eddy Simulation, China Communications Press, Beijing, China, 2010.

[20] Z.-W. Zhu, "Feasibility investigation on prediction of vortex shedding of flat box girders based on 2D RANS model," China Journal of Highway and Transport, vol. 28, no. 6, pp. 24-33, 2015.

[21] D. Fransos and L. Bruno, "Determination of the aeroelastic transfer functions for streamlined bodies by means of a NavierStokes solver," Mathematical and Computer Modelling, vol. 43, no. 5-6, pp. 506-529, 2006.

[22] H. Lugt, "The dilemma of defining a vortex," in Recent Developments in Theoretical and Experimental Fluid Mechanics, Springer, Berlin, Germany, 1979.

[23] M. Rütten, T. Alrutz, and H. Wendland, "A vortex axis and vortex core border grid adaptation algorithm," International Journal for Numerical Methods in Fluids, vol. 58, no. 12, pp. 13791405,2008

[24] J. C. R. Hunt, A. A. Wary, and P. Moin, "Streams and convergence zones in turbulent flows," Center for Turbulence Research CTR-S 88, 1988.

[25] M. S. Chong, A. E. Perry, and B. J. Cantwell, "A general classification of three-dimensional flow fields," Physics of Fluids A. Fluid Dynamics, vol. 2, no. 5, pp. 765-777, 1990.

[26] J. Jeong and F. Hussain, "On the identification of a vortex," Journal of Fluid Mechanics, vol. 285, no. 4, pp. 69-94, 1995.

[27] K. Q. Zhu, B. G. Tong, and X. Y. Yin, Theory of Vortex Motion, University of Science and Technology of China Press, Hefei, China, 2nd edition, 2009.

[28] B. C. Huang, Principle and Application of Structural Wind Resistance Analysis, Tongji University Press, Shanghai, China, 2007.

[29] Chinese Standard, "Guidelines for design of highway safety facilities," JTG/T D81-2006, China Communications Press, Beijing, China, 2006.

[30] CJJ 11-2011, Code for Design of Municipal Bridge, China Building Industry Press, Beijing, China, 2011.

[31] D. C. Vaz, R. A. B. Almeida, E. Didier, A. P. V. Urgueira, and A. R. J. Borges, "Improving the aerodynamic performance of Vila-Real Bridge deck-section," Journal of Wind Engineering and Industrial Aerodynamics, vol. 156, pp. 72-83, 2016.

[32] Y. G. Sun, The Analytical Approach and Application Study of Vortex-Induced Vibration of Long-Span Bridge Based on Partial Correlation, Southwest Jiaotong University, Chengdu, China, 2013. 


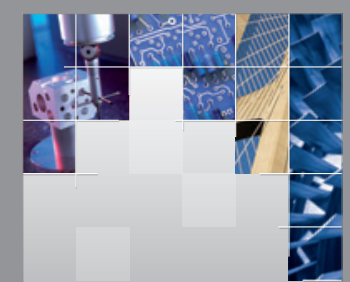

\section{Enfincering}
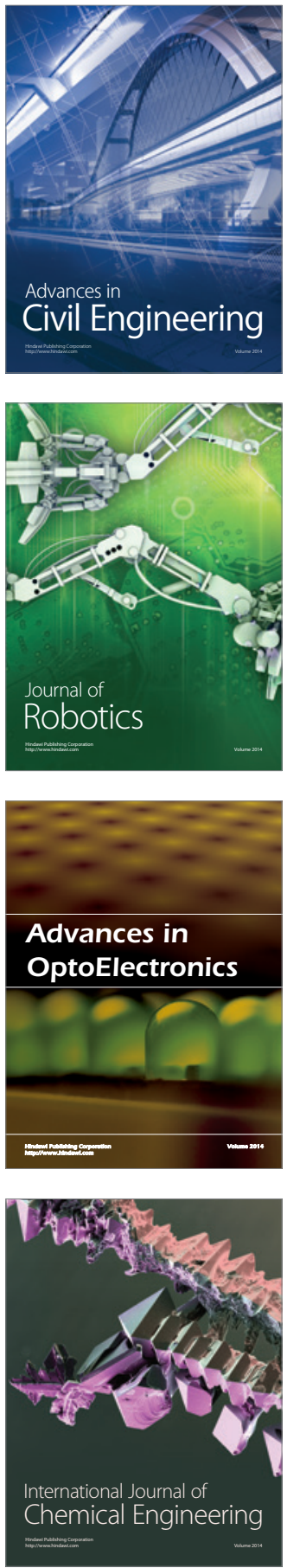

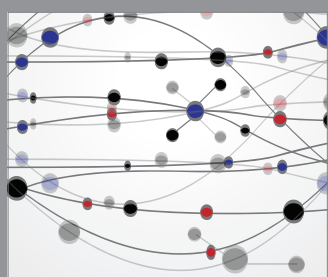

The Scientific World Journal

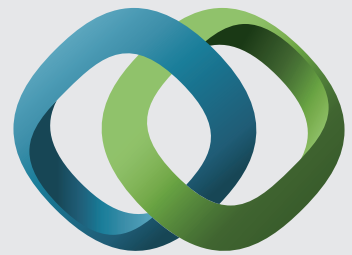

\section{Hindawi}

Submit your manuscripts at

https://www.hindawi.com
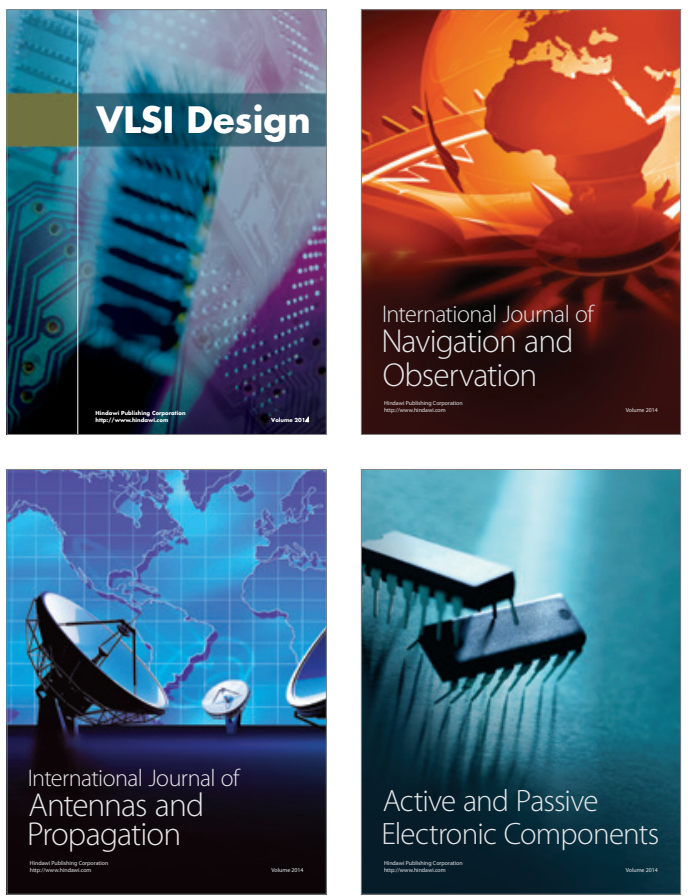
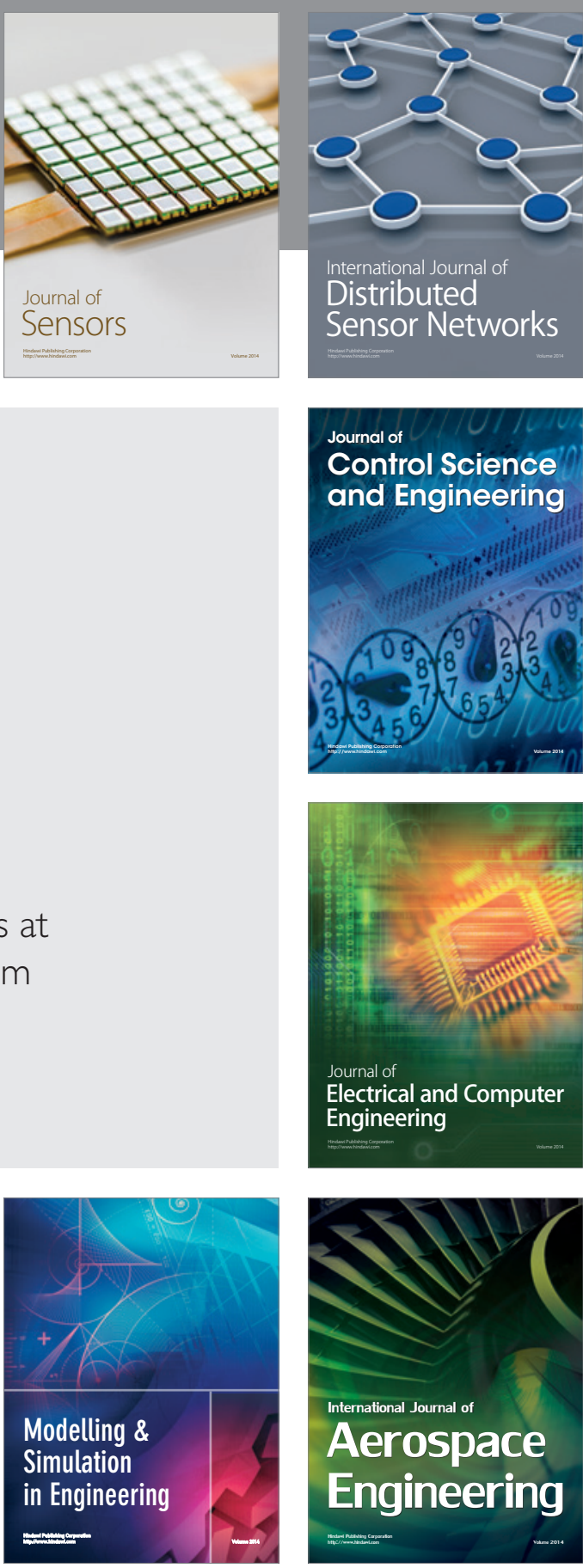

International Journal of

Distributed

Sensor Networks

$-$

Joumal of

Control Science

and Engineering
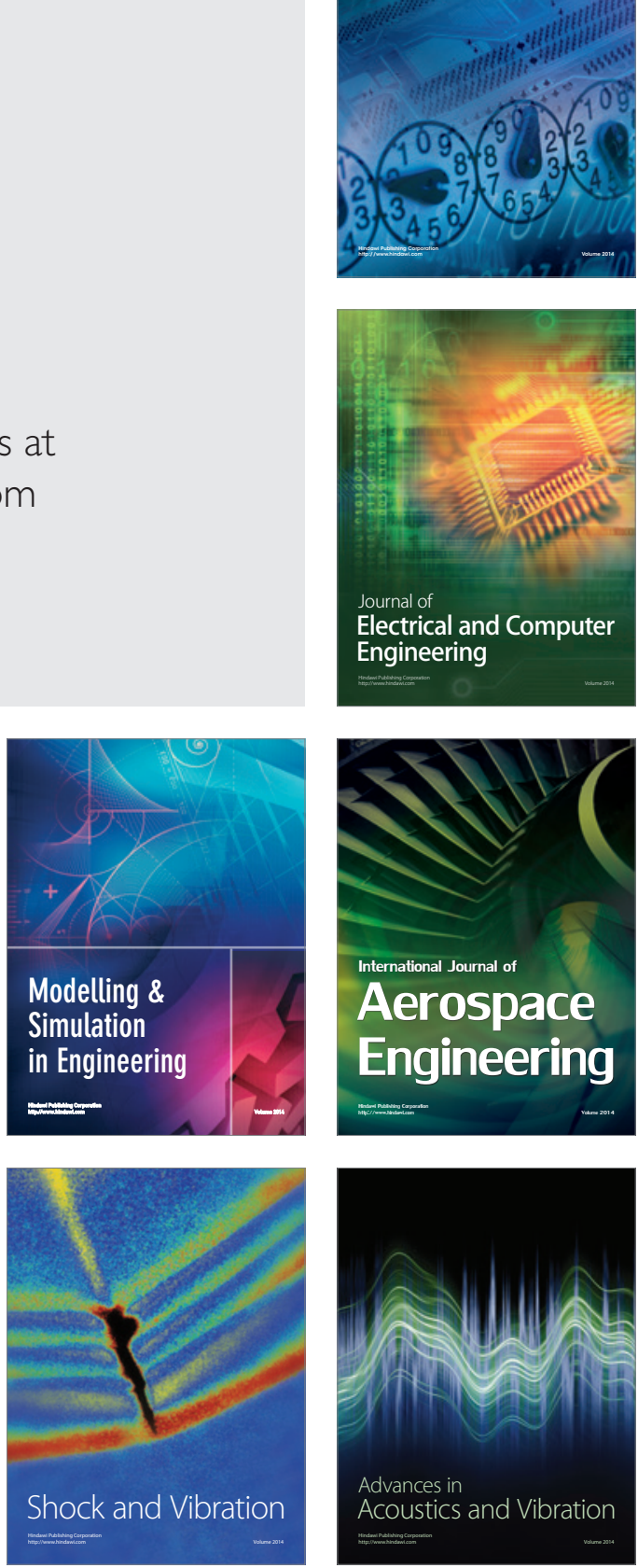